\title{
10
}

\section{The Terrestrial Vertebrate Remains}

\author{
Philip J. Piper, Noel Amano Jr., Shawna Hsiu-Ying Yang and Terry 0'Connor
}

This chapter describes the analysis and interpretation of the terrestrial vertebrate remains from the islands of Itbayat and Sabtang. The results indicate that pigs were present in the islands from the earliest recognised phases of colonization and were the only large mammal resource during the prehistoric period, from at least $1200 \mathrm{BC}$ until after $\mathrm{AD} 1000$, when the goat was introduced into the islands. Dogs appear to be present by at least $500 \mathrm{BC}$, as well as a species of civet cat from a similar or slightly earlier date on Itbayat, that has now been extirpated from the island.

\section{Methods}

In total, 3557 fragments of terrestrial vertebrate (including marine turtle) remains were recovered during the excavations at the sites of Anaro, Torongan, Savidug Dune Site and Pamayan. Dry sieving using a $5 \mathrm{~mm}$ mesh was undertaken at all sites except Sunget, where the hardness and high clay content of the archaeological deposits made it virtually impossible to pass them through a sieve. Bulk wet sieving was ruled out by the lack of any available water. This use of a fairly coarse sieve mesh has influenced the amount of information recoverable on pre- and post-depositional processes acting upon the vertebrate assemblages, and on the community structure and composition of the animals present. This was especially the case for taxa within the classes of small terrestrial vertebrates and fish. Nevertheless, considerable amounts of meaningful information about human subsistence were recovered from the animal bone assemblages.

For the purposes of this study, taphonomic terminology follows Piper (2003), modified from Lyman (1994). Important taphonomic alterations, some teeth, and other selective elements were photographed and archived using a Pentax M20 digital camera. The more interesting natural and anthropic modifications were also studied using a digital camera attached to a trinocular microscope, and butchery patterns of special interest were photographed. These marks were identified in morphological terms according to the conventions established by Potts and Shipman (1981), but we acknowledge that materials other than stone (the only material studied by Potts and Shipman) could potentially have been used during butchery. In this study, cut marks are identified as single, or multiple sub-parallel, linear incisions into the cortical surface of the bone, typically displaying regular V-shaped profiles. Chop marks are generally wider and deeper, and vary in their morphologies dependent on the direction and angle of strike.

The maximum length of each bone fragment was measured, unless there was modern breakage. This allowed us to identify varying rates of fragmentation between sites. Distinctive fragments of 
mammal and reptile bone were all identified to the highest taxonomic level possible, using the comparative assemblages housed in the Department of Archaeology, University of York, and the zooarchaeology laboratory at the University of the Philippines.

Most of the criteria for biometric analyses of suid and caprid post-cranial elements follow von den Dreisch (1976). However, due to the fragmentary nature of the bone assemblage, a number of alternative measurements have also been used. These measurements are archived and available for future study if requested.

For teeth, a standard length measurement was taken, and then the breadth of each molar column was measured. To interpret possible body-size changes in relation to domestication and animal management, the dimensions of the Batanes dp4s (deciduous $4^{\text {th }}$ premolars) and $1^{\text {st }}(\mathrm{M} 1 \mathrm{~s})$ to $3^{\text {rd }}$ molars (M3s) have been compared with modern comparative specimens from China (data collected by J. Ochoa and P.J. Piper, Table 10.1) and Taiwan (unpublished data kindly provided by Keith Dobney, University of Aberdeen). Similar measurements were used for the length and breadth of caprid teeth. As few comparative data for caprids currently exist, and since no previous research has been carried out into body-size changes within Mainland and Island Southeast Asian caprine populations, these measurements are compared with the only other dataset currently available, from the $14^{\text {th }}-17^{\text {th }}$ century AD East Timorese sites of Vasino and Macapainara (Amano and Piper 2011; Piper and Amano 2011). All references to tooth wear stages reported in the text and tables are from Grant (1982), and relative ages of pigs are from Bull and Payne (1982).

Linear enamel hypoplasia (LEH) is a defect acquired during the developmental stage of molars that manifests itself as rows of pits and linear depressions in the enamel surface. These defects are considered to indicate physiological stress, and in particular nutritional deficiency, during the early growth of an animal (Dobney et al. 2007). LEH is not randomly located on teeth, but occurs at specific heights on the molar crown. It has been suggested that birth and weaning are the direct causal effects of two distinctive peaks in LEH on the $1^{\text {st }}$ permanent molar. Other defects on the $2^{\text {nd }}$ and $3^{\text {rd }}$ permanent molars are possibly related to the effects of nutritional stress during the animal's first and second winters respectively (Dobney and Ervynck 1998). Studies show that there are strong differences in the frequencies of stress-induced LEH that are useful indicators of former husbandry practices and environmental conditions (Ervynck and Dobney 1999). Importantly, there also appear to be marked differences in the levels of stress suffered by domestic pigs in comparison to their wild counterparts, and these can be used to differentiate between the two (Dobney et al. 2007). All pig molars were studied under a low-powered microscope for any LEH defects.

\section{Taphonomic observations}

\section{Anaro: Taphonomy}

Anaro produced the largest bone assemblage recovered from Itbayat, with a total of 1316 identified terrestrial vertebrate remains and a further 10 indeterminate fragments. Due to logistical problems of access to freshwater and the compact, sticky nature of the clay substrate the deposits from Anaro were dry-sieved through a $5 \mathrm{~mm}$ mesh. This has inevitably had a serious impact on the recovery of small bone fragments, and selective hand collection probably explains, at least in part, the low percentage of indeterminate fragments recovered (i.e. there was selective recovery of bones deemed identifiable by the archaeologists). 


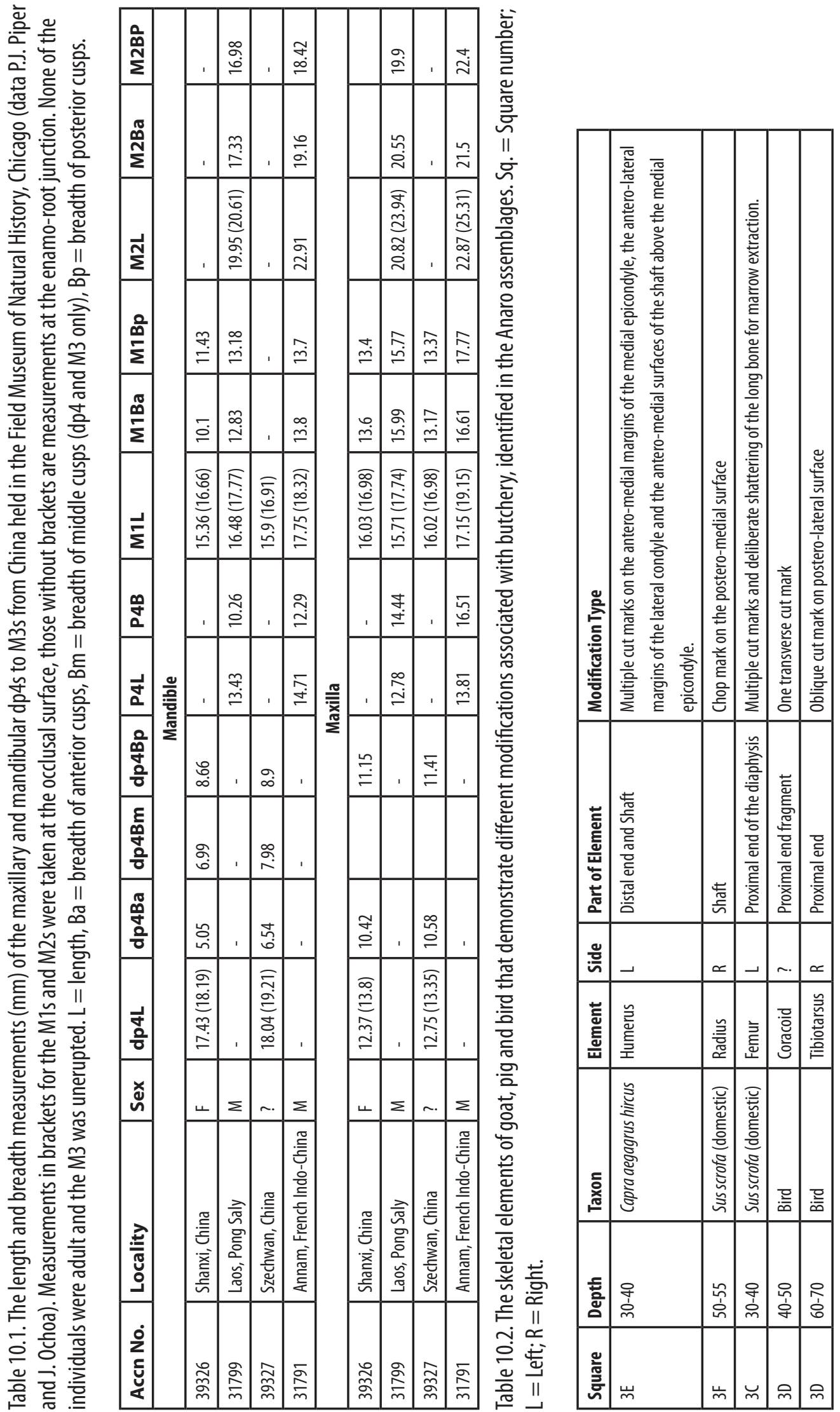




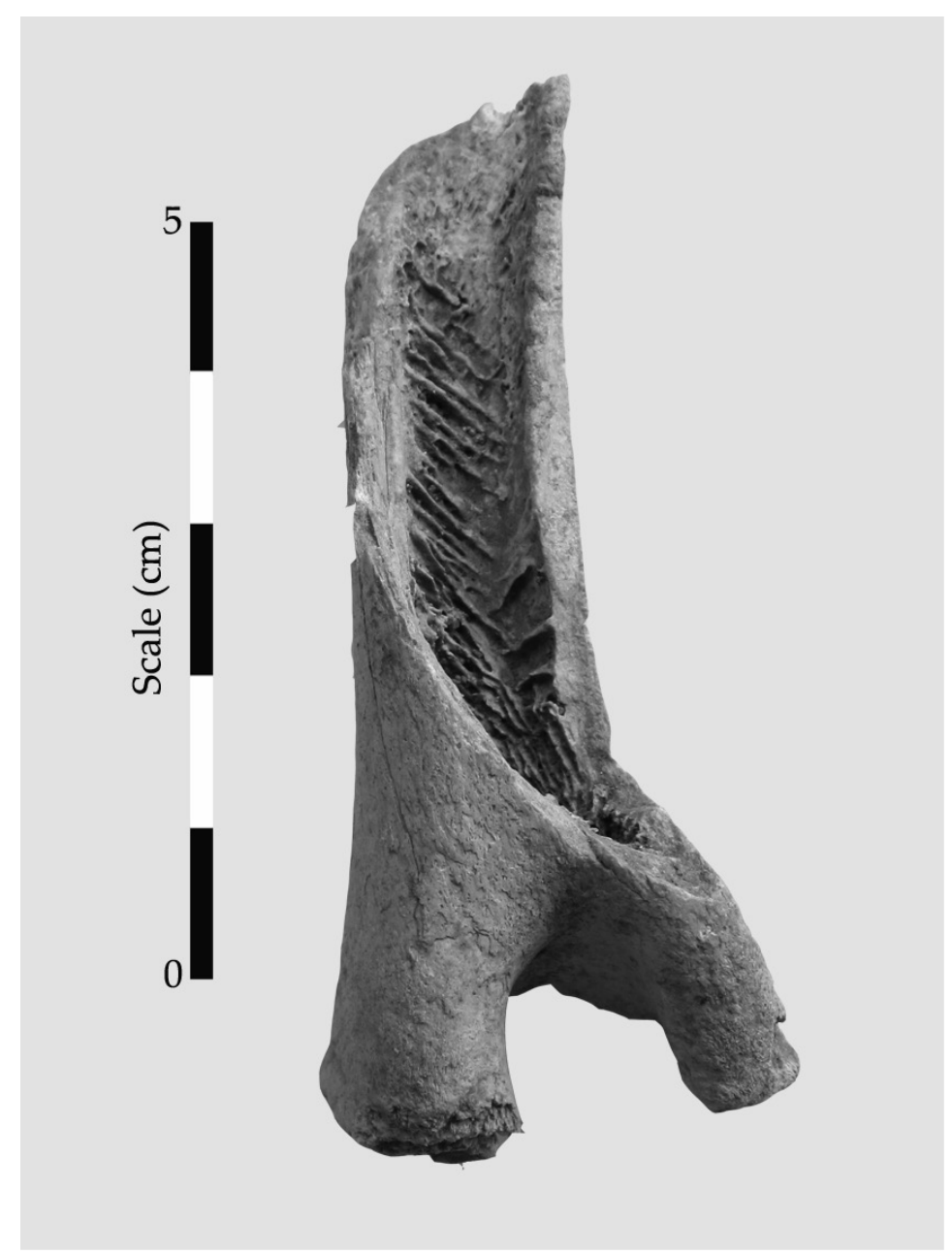

Figure 10.1. A pig right humerus from Savidug B11 $(60-70 \mathrm{~cm})$ demonstrating a spiral fracture and 'tearing' that has caused the loss of the posterior and lateral surfaces of the bone whilst it was still green and fresh.

Source: Philip Piper.

In terms of spatial distributions, the small rock shelter of Anaro 3 produced the highest number of animal bones, and discussion will primarily focus on this site. Close examination of surfaces and internal (cross-sectional) structure showed that most fragments were in relatively good condition, demonstrating little diagenetic breakdown of cortical bone matrices. The large- and intermediate-sized mammal bones consisted primarily of isolated teeth and bone fragments between 20 and $50 \mathrm{~mm}$ in length, indicating quite intensive fragmentation. Most breaks were either transverse, irregular transverse, or irregular, and occurred following discard when the bones were old and dry. Some fractures, however, were associated with impact scars and negative flake scars characteristic of deliberate human breakage - this type of butchery is commonly associated with marrow extraction (Johnson 1985; see Fig. 10.1 for an example from Savidug Dune Site).

Abrasion and rounding of articular ends and fracture surfaces indicate some degree of subsurface and post-depositional movement (Marshall 1989). Longitudinal cracking and splitting of cortical bone surfaces indicate extensive subaerial weathering and possibly trampling of most bone fragments from each grid square (Behrensmeyer 1978). For example, with the exception of two burnt bones from Anaro 3D, all the bone shows various stages of weathering, indicating that 
there was possibly some delay between deposition and eventual burial. Furthermore, surfaces were often pitted and root etched, implying quite shallow incorporation, i.e. burial within the active root-zone (Olsen and Shipman 1988).

Nineteen fragments of bone from six different skeletal elements demonstrate single or multiple cut marks and/or chop marks close to articular ends, associated with butchery (Tables 10.2 and 10.3). For example, the distal end (fused) and shaft of a goat left humerus from Anaro 3E (30-40 $\mathrm{cm})$ possesses cut marks on the antero-medial margins of the medial epicondyle, the anterolateral margins of the lateral condyle, and the antero-medial surfaces of the shaft above the medial epicondyle (Fig. 10.2). Cut marks in these locations suggest that the humerus was severed from the radius and ulna. In addition, several parallel cut marks were identified on the inferior surfaces of the diaphysial shaft, below the proximal articular end (unfused), of a pig left femur (Anaro $3 \mathrm{C}: 35-40 \mathrm{~cm}$ ). The cut marks indicate that the femur was physically removed from the pelvis during butchery. Yet again, the proximal end of a chicken-sized avian right tibiotarsus (although not a chicken) from Anaro 3D $(60-70 \mathrm{~cm})$ possessed a single oblique cut mark on its posterolateral surface. A proximal end fragment of chicken-sized coracoid also has a single transverse cut mark across its surface. These records clearly demonstrate that the local inhabitants of Anaro were hunting and butchering the local and/or introduced avifauna on Itbayat Island.

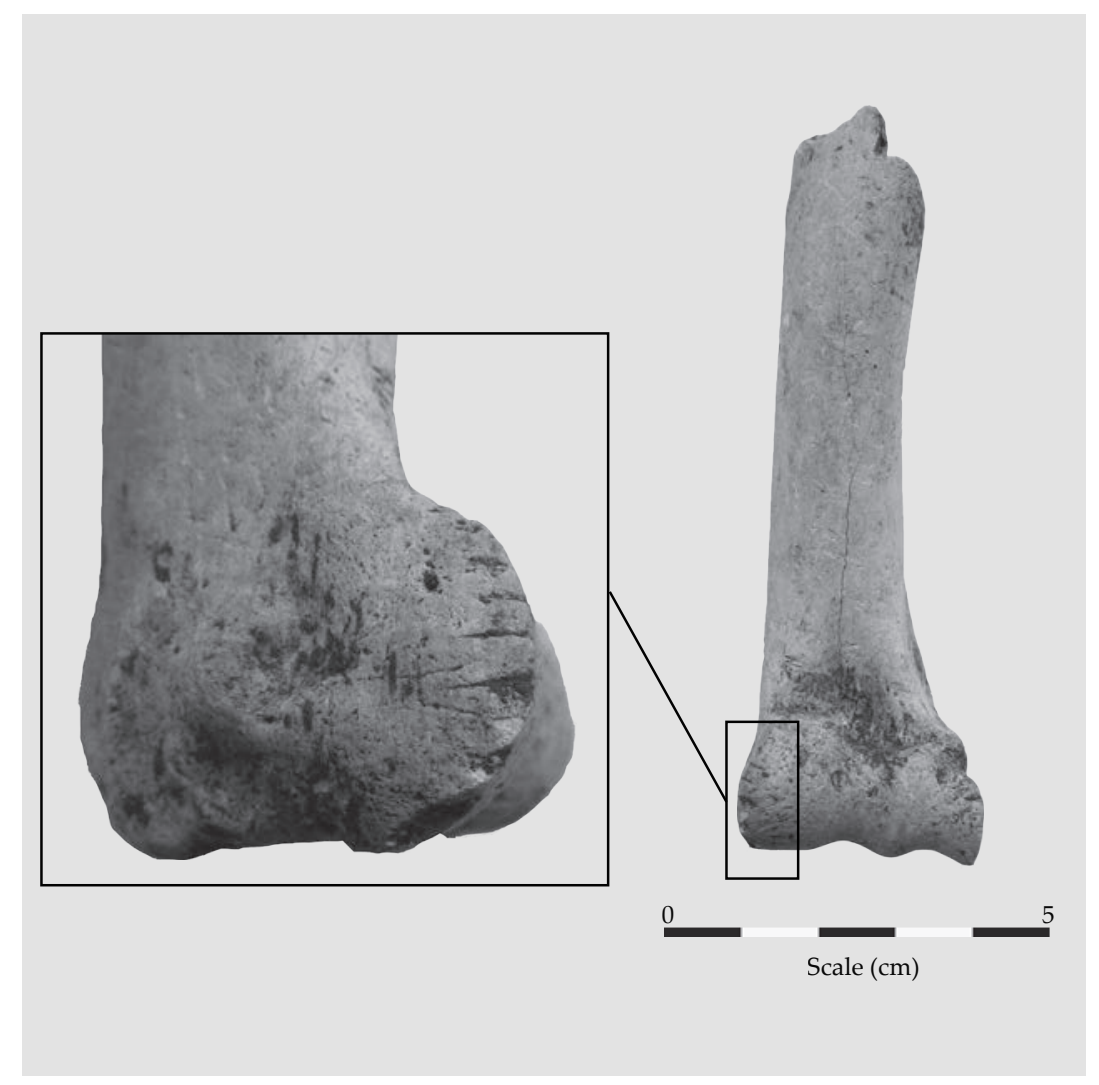

Figure 10.2. Close up of the cut marks on antero-medial margins of the medial epicondyle of a goat left humerus from Anaro $3 \mathrm{E}(30-40 \mathrm{~cm})$.

Source: Philip Piper.

The vertebrate assemblage also contains several bones that exhibit parallel patterned grooving across articular surfaces and along shafts, both characteristic of rodent gnawing. These types of modification were observed, for example, on the distal end of a pig femur (Anaro 5: 0-5 cm). They feature narrow, contiguous shallow scrape marks across their surfaces and articulations. 
The breadths and depths of the incisor grooves are consistent with those produced by murids, probably rats, a modification also observed in the Savidug and Pamayan assemblages on Sabtang Island (see Fig. 10.3 for an example from Savidug Dune Site).

A single fragment of the neck and blade of a pig scapula (Anaro 3C: $60-65 \mathrm{~cm}$ ) demonstrates shallow indentations around the periphery of the fracture margins and slight thinning of the breakage edges. These are features characteristic of carnivore gnawing (Lyman 1994: 206-216).

\section{Torongan Cave: Taphonomy}

The bone assemblage from Torongan demonstrates very different biostratinomic and postdepositional modifications from those identified at Anaro and Sunget. Many bone fragments are slightly or moderately eroded, causing shallow pitting and the smoothing and rounding of surfaces and fracture margins (Piper 2003). These modifications are characteristic of animal bones that have been subjected to reworking and re-deposition as a result of fluvial action. This interpretation is supported by the occurrence of isolated pieces of bone from similar depths that vary considerably in their state of preservation, with some appearing mid to dark brown in colour and highly weathered and eroded, whilst others have the appearance of being of more recent origin. This supports the sedimentary analysis and archaeological interpretation that these deposits represent in-washed soil from above the cave (chapter 2).

\section{Savidug Dune Site: Taphonomy}

In total, 1454 bone fragments of terrestrial vertebrate were recovered from all the layers identified at the Savidug Dune Site. Of these, 1190 (82\%) could be identified as mammal, reptile or bird, with another $264(18 \%)$ being indeterminate small fragments. 546 bones were securely provenanced to cultural layer 2, dating to $\mathrm{AD} 1000-1500$ based on the trade ware pottery recovered. Another 406 were recorded in the lower cultural layer 4 at 90 to $150 \mathrm{~cm}$, dated to between 560 and 390 BC (WK 21809). Just 47 bones were recovered from layer 5 (below 150 $\mathrm{cm}$ ), correlated with a charcoal date of 1130-930 BC (WK 21810) (Chapter 5).

Table 10.3. The skeletal elements, not confidently identified to taxon, that demonstrate modifications associated with butchery from Anaro.

\begin{tabular}{|l|l|l|l|}
\hline Square & Depth & Element & Modification Type \\
\hline 9 & $10-20$ & rib & One transverse cut mark \\
\hline 14 & $30-40$ & long bone fragment & One oblique cut mark \\
\hline $3 G$ & $30-40$ & long bone fragment & Two transverse chop marks \\
\hline $3 D$ & $40-50$ & long bone fragment & One transverse cut mark \\
\hline $3 F$ & $50-55$ & long bone fragment & Four transverse cut marks \\
\hline $3 D$ & $50-60$ & long bone fragment & Two Transverse cut marks \\
\hline $3 G$ & $50-60$ & long bone fragment & Transverse cut mark \\
\hline $3 D$ & $60-70$ & humeral shaft fragment & Transverse cut mark \\
\hline $3 G$ & $70-80$ & long bone fragment & Transverse chop mark and oblique cut mark \\
\hline $1 C$ & $0-10$ & Rib & Two dorso-ventrally orientated cut marks across the surface of the bone. \\
\hline $1 C$ & $10-20$ & Rib & Single cut mark on the medial surface. \\
\hline 3 & $40-45$ & Rib & Two chop marks of the lateral surface \\
\hline $3 \mathrm{~A}$ & $40-50$ & Rib & Two transverse cut marks on the lateral surface. \\
\hline 3 & $30-35$ & Indet. & Multiple transverse cut marks across the bone surface. \\
\hline
\end{tabular}

The bone accumulations in layers 2 and 4 are further spatially differentiated, with the layer 2 assemblage predominantly located in Trenches A-C and K-N. The highest layer 2 concentrations occur in the B and C squares and account for 698 (78.9\%, including fish) of the recorded bone fragments. Bones below $90 \mathrm{~cm}$ (layers 4 and 5) are almost exclusively from Trench QR 7-9, with 
1080 (99\%, including fish) of the 1091 fragments recorded. Only six fragments of bone were recorded in QR 7-9 above $90 \mathrm{~cm}$, suggesting that cultural layer 2 was almost completely absent from this trench in terms of bone deposition.

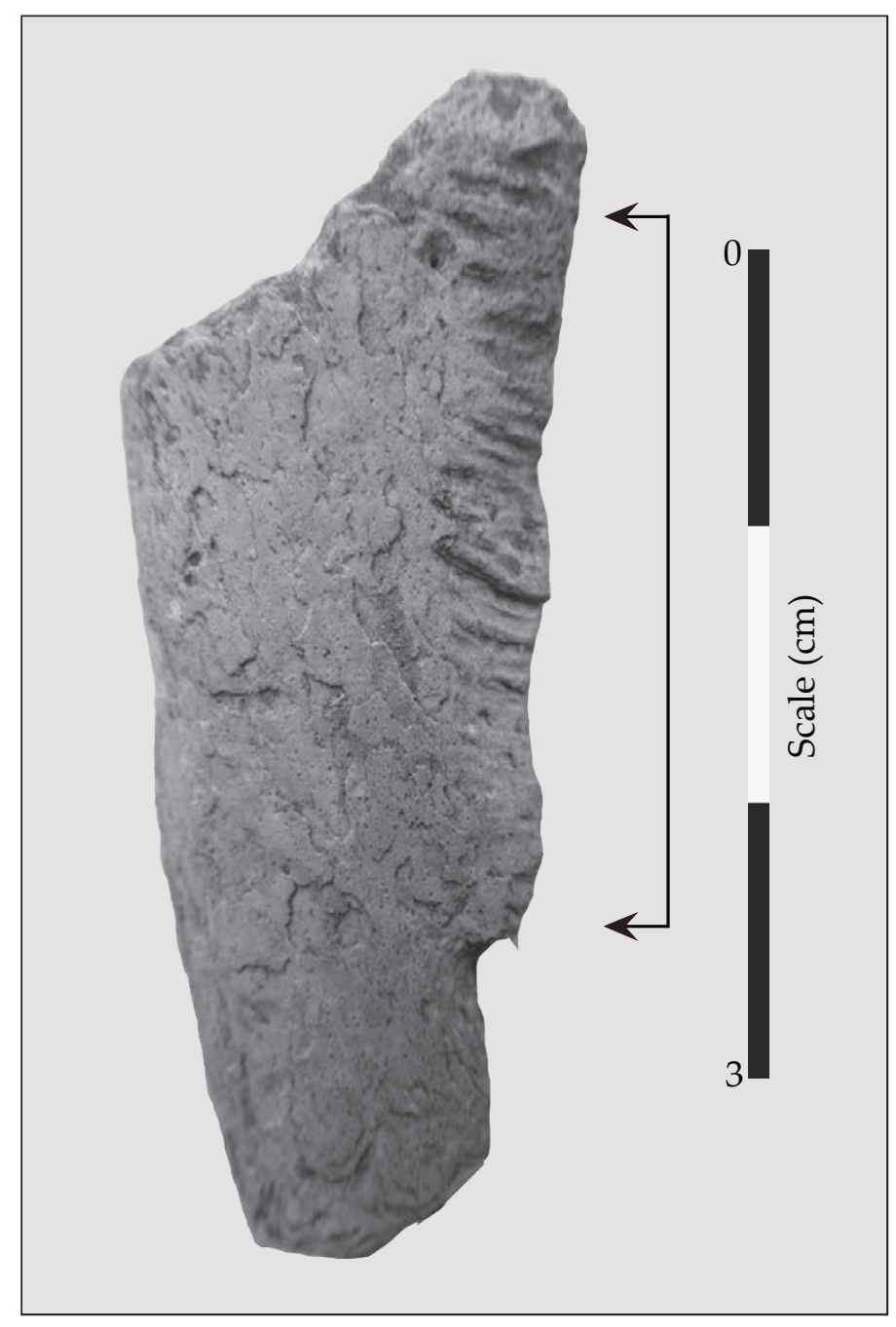

Figure 10.3. Fragment of bone from Savidug Dune Site B9 $(80-90 \mathrm{~cm})$ demonstrating the parallel grooving along a fracture margin characteristic of rodent gnawing (demarcated by the arrows).

Source: Philip Piper.

Bone fragment size in large mammals and reptiles is consistent across trenches and depths, with none of the excavated spits or layers having substantially larger or smaller bones than the average. A remarkably high proportion of the bones demonstrate surface weathering. In layer 2, the highest proportion of weathered and abraded mammal bone, with the greatest severity of modification, comes from the upper $20 \mathrm{~cm}$ (75\%). Below this level the bones are characteristically around $40-50 \%$ weathered and abraded. In layer 4 the $90-100 \mathrm{~cm}$ spit has just $36 \%$ of weathered and abraded bones, but succeeding spits have increasing numbers of slight or moderately weathered fragments. Below 140-150 cm almost all bone fragments show some evidence of slight, moderate or severe levels of weathering.

Two long bone shaft fragments from Trenches C9 $(40-50 \mathrm{~cm})$ and B10 $(50-60 \mathrm{~cm})$, and a pig left calcaneus (B10 50-60 cm), radial shaft fragment $(\mathrm{C} 1160-70 \mathrm{~cm})$, shaft of a 3rd or $4^{\text {th }}$ metapodial (B9 80-90 cm), and basal medial phalanx (QR 7-9 110-120 cm), all display the characteristic parallel patterned grooving at fracture margins or along edges associated with 
rodent gnawing. The size and morphology of the grooves would suggest that rat-sized or smaller rodents were responsible for inflicting the observed damage (Fig. 10.3). The concentric pitting and localised thinning of bone around the fracture margins at one end of a left pig humeral shaft fragment from B11 $(50-60 \mathrm{~cm})$ is tentatively identified as possible dog gnawing.

Forty-eight fragments of bone from 11 different skeletal elements demonstrate various modifications associated with butchery (Tables 10.4 and 10.5). The evidence consists primarily of fine transverse or oblique parallel cut marks on bone surfaces, often close to articular ends. For example, a pig left femoral shaft fragment from close to the distal end in C11 $(60-70 \mathrm{~cm})$ possesses several small cut marks on the postero-lateral margins, and a fragment of unfused right ilium in C9 $(40-50 \mathrm{~cm})$ has four transverse cut marks on the dorsal surfaces. In addition, a few bones such as the distal end and midshaft of a pig right femur from $\mathrm{C} 11(60-70 \mathrm{~cm})$ have been hacked through, presumably to facilitate marrow extraction. The spiral fracturing and longitudinal flaking of a pig right humeral shaft from B1 $(50-60 \mathrm{~cm})$ is also a good indication of deliberate fresh bone breakage for marrow extraction (Fig. 10.1). Overall, the butchery evidence suggests systematic dismemberment of carcasses and some long bone breakage for marrow extraction. In addition, 35 fragments of burnt bone were recorded throughout the bone assemblages, but specific concentrations could not be identified.

Overall, the taphonomic analysis would suggest that the Savidug Dune Site bone assemblages represent the remains of animals butchered and discarded by humans. The high incidence of bone surface weathering and rodent gnawing is consistent with bones that were not deliberately buried, but discarded on the ground surface. Their burial took an extended period of time after disposal.

\section{Pamayan: Taphonomy}

Of the 762 bone fragments excavated from Pamayan, 264 (34.6\%) were recorded as mammal, $14(1.8 \%)$ as bird, and there was one worked piece of turtle plastron. The other $483(22.7 \%)$ fragments were recorded as indeterminate, although many fragments were probably small pieces of mammal bone.

The average fragment length in mammal and bird bone was just $2.7 \mathrm{~cm}$, demonstrating the severity of fragmentation that has restricted identification in all classes of vertebrate. Similar observations were made in chapter 4 concerning the high levels of fragmentation of shells, especially small cowrie shells, in this site, which dates to the end of prehistory in Batanes. Within the mammals, even the pig and goat teeth were heavily fragmented. Almost all fragments of bone demonstrate varying stages of weathering indicating that they were left exposed on the ground surface prior to burial.

Butchery is rare in these very heavily fragmented assemblages, but the proximal end of a goat left femur from $65-70 \mathrm{~cm}$ possesses two transverse cut marks on the lateral margins. This same fragment also has evidence of rodent gnawing along the antero-lateral margins, a further indication that the bones remained on the ground surface prior to burial. 


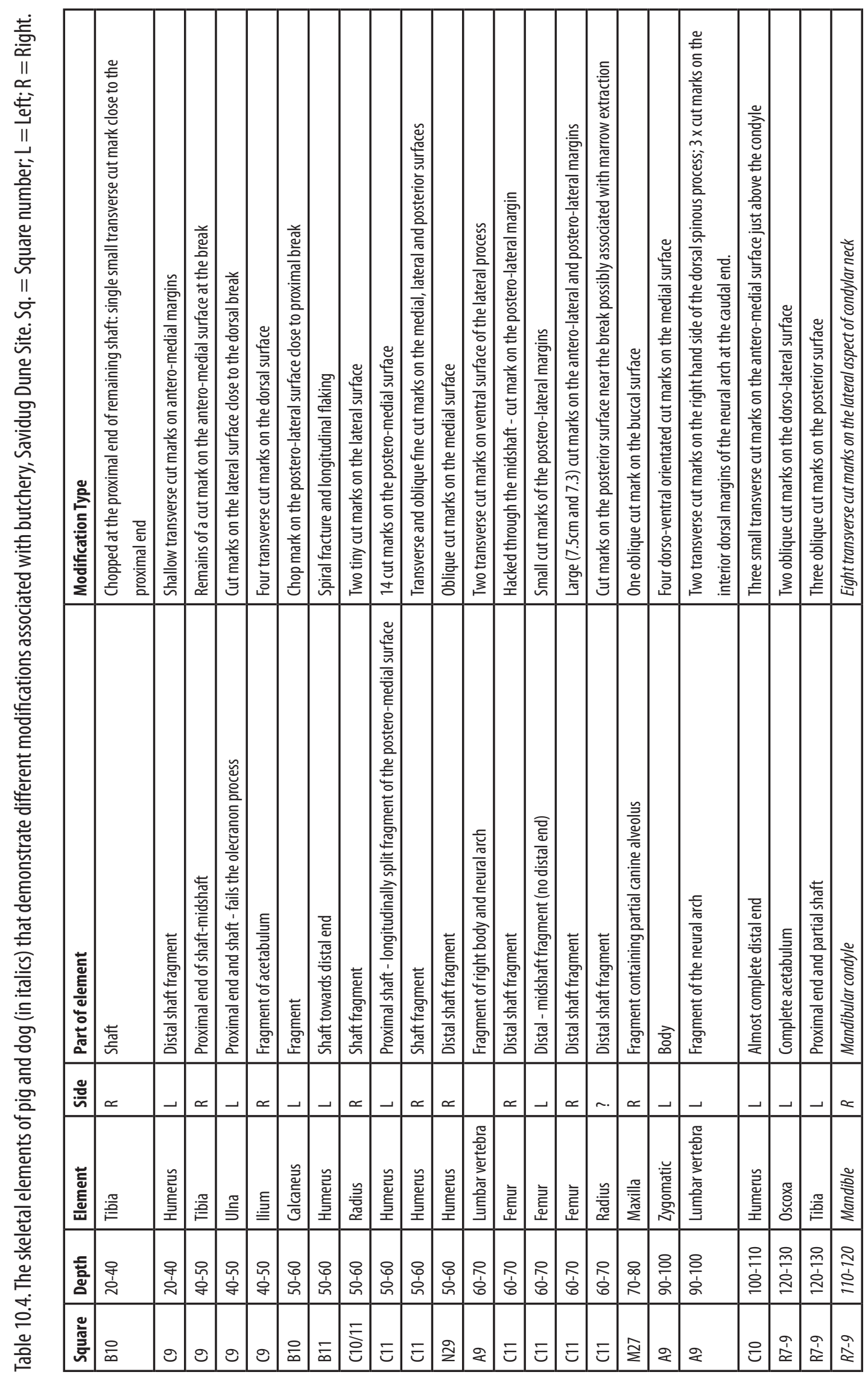




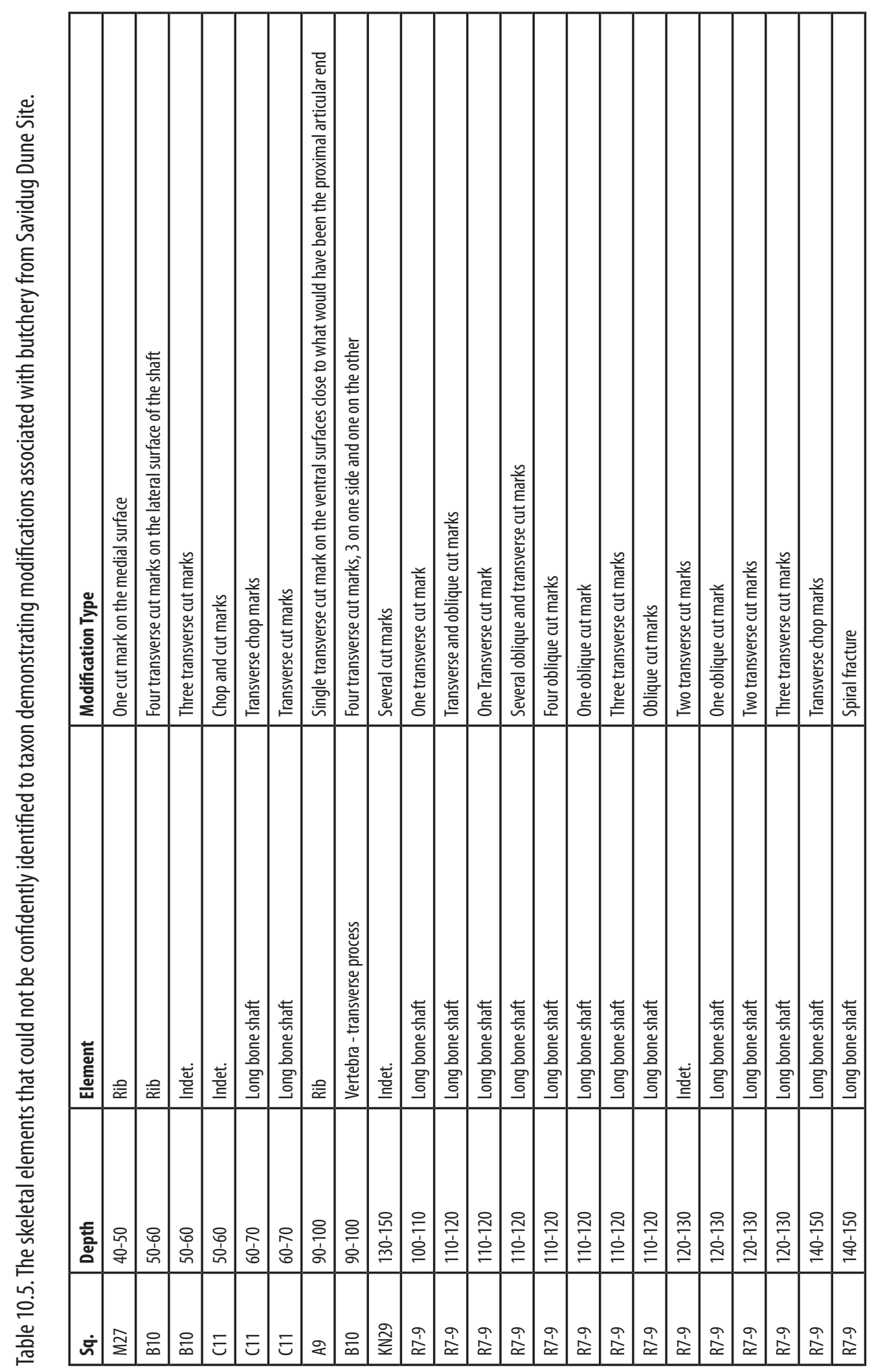




\section{Taxonomic identifications}

\section{Anaro: Taxonomy}

Of the 1316 bone fragments from Anaro, 307 (23.3\%) could be identified to family or a lower taxonomic level. The highest proportion of identifiable skeletal elements was recovered from Anaro $3(\mathrm{~N}=220$; Table 10.6). The absence of goat below $50 \mathrm{~cm}$ in most trenches of Anaro 3 would seem to be consistent with the radiocarbon dating (chapter 5), which shows that the basal deposits pre-date the introduction of caprines, extending from $c .1000 \mathrm{BC}$ to beyond $\mathrm{AD} 500$.

The pig was the most frequently occurring taxon $(\mathrm{N}=224)$ and was present at all depths from $110-120 \mathrm{~cm}$ in Anaro 6 to the subsurface in many trenches. In Anaro 3 there was a slight concentration of pig bones between 50 and $80 \mathrm{~cm}$, perhaps indicating more intensive deposition of bone during this period, which most likely preceded the introduction of the goat towards the end of the 1st millennium $\mathrm{AD}$ (see below).

Both male and female pigs are represented at Anaro and can be distinguished by their canine morphologies. It is difficult to ascertain with any confidence whether the remains of entire carcasses were deposited at Anaro, due to the dispersed nature of the faunal remains. Certainly, the small compact extremities and loose teeth have survived the best (NISP $=155 / 224)$. Nevertheless, fragments of most body parts are present. Beyond those illustrated in Fig. 10.4, several small pieces of vertebrae and rib are almost certainly from pigs, especially below $50 \mathrm{~cm}$ where the goat is absent. Overall, it would seem that most major skeletal elements were discarded at Anaro.

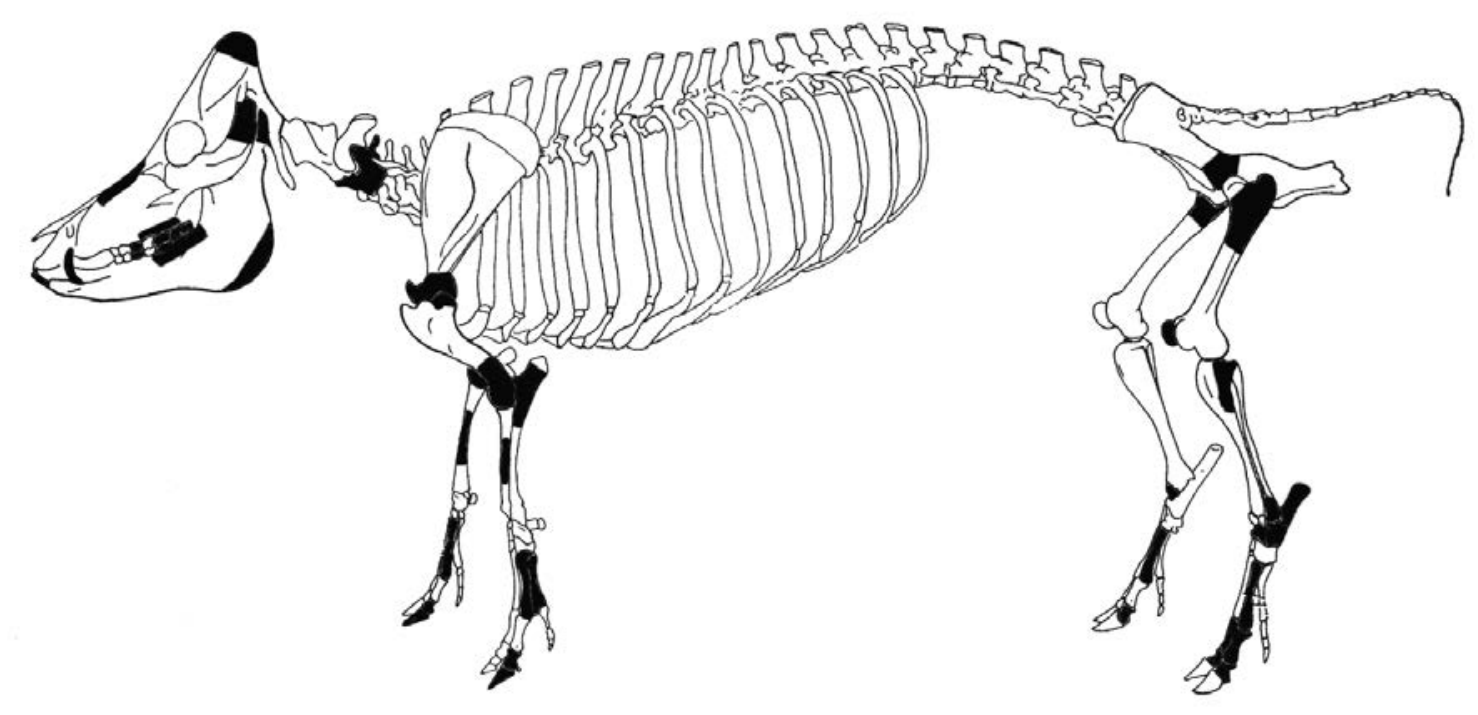

Figure 10.4. The pig body part representation (shaded) from Anaro.

Source: Philip Piper. 


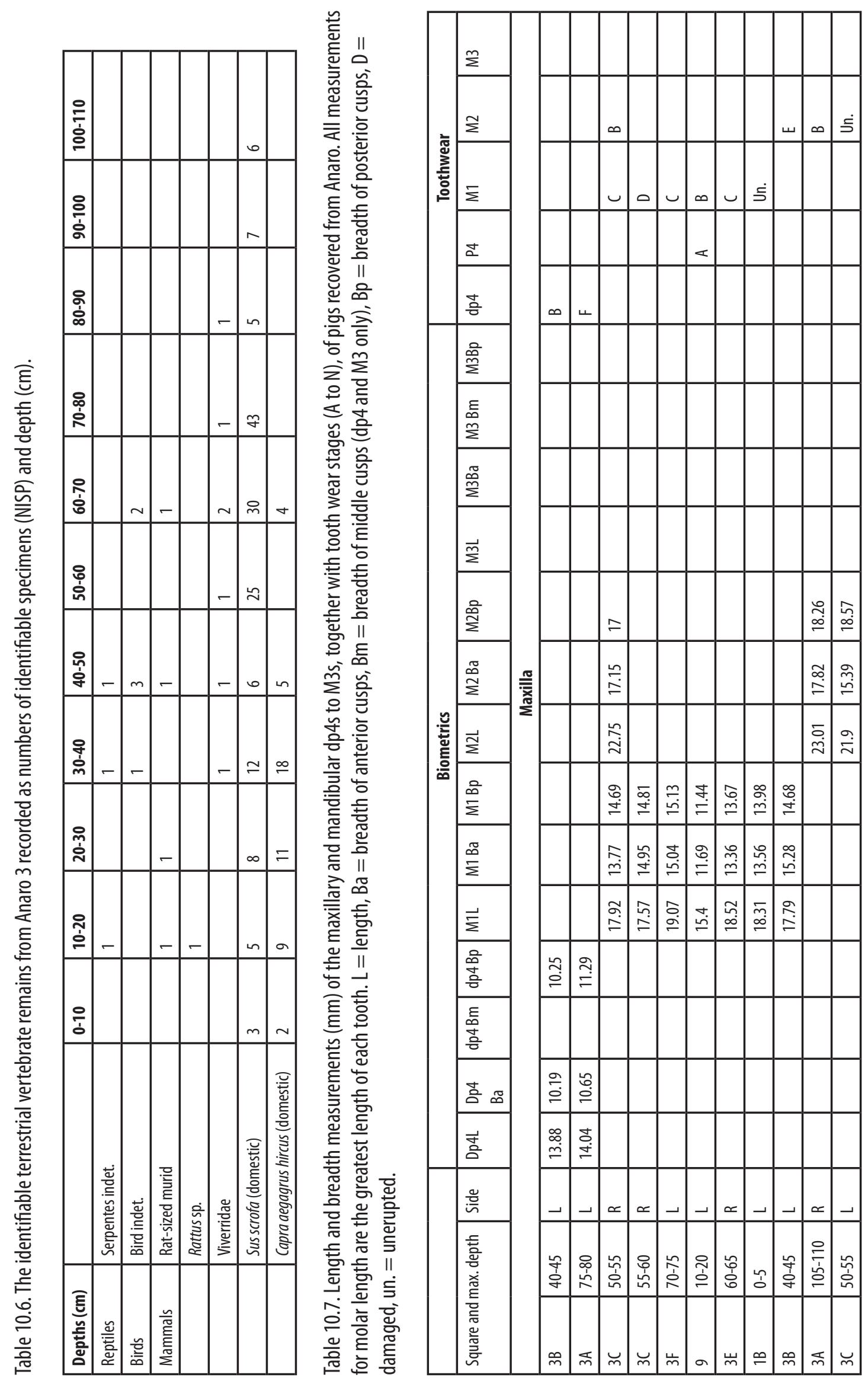




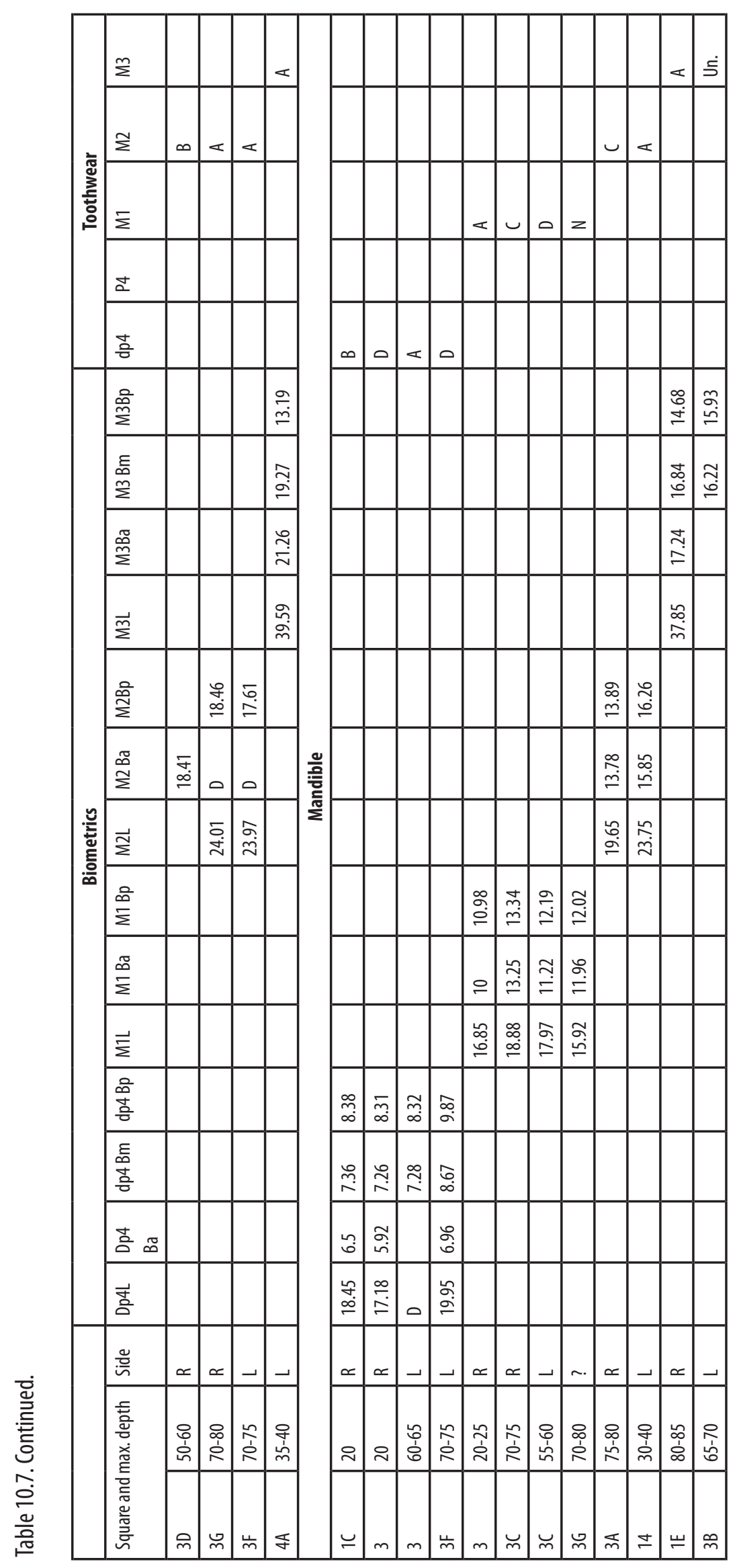


Stages of epiphysial fusion suggest that pigs from a variety of ages are represented at Anaro. For example, a left ulna from 3E $(60-65 \mathrm{~cm})$, a left humerus from $3 \mathrm{D}(60-70 \mathrm{~cm})$ and a radius (unsided) from 4A $(40-50 \mathrm{~cm})$ were all so small and undeveloped that they could only be from neonates. A left distal humeral diaphysial fragment from $3 \mathrm{E}(30-40 \mathrm{~cm})$, a right humeral shaft fragment with unfused articular end from $3 \mathrm{~B}(70-75 \mathrm{~cm})$, a damaged left dp4 with no occlusal wear (Grant Stage A) from 3 $(10-20 \mathrm{~cm})$, and an unerupted mandibular first molar from 1B (0-5 $\mathrm{cm})$, represent at least three juvenile individuals based on spatial and chronological separation. Furthermore, tooth eruption and dental wear of the dp4s and permanent molars suggests individuals of a variety of ages, from perhaps a few months to 3 years old. But no pigs appear to have reached a substantial age before death (Table 10.7). The high proportion of juvenile or subadult pigs is consistent with a managed rather than a wild or feral pig population. However, the presence of neonatal and very young pigs of just a few months of age is not a pattern of kill-off seen in the bone assemblages of Layers 2 and 4 at Savidug Dune Site on Sabtang Island. Perhaps it indicates different methods of pig stalling and management on the two islands, and during different periods of occupation (see below).

Biometrical analyses of the Anaro pig molars indicates that they fall within the upper range of the Eurasian wild boar (Sus scrofa) recorded in Taiwan and China, suggesting that the morphotype represented in the Batanes was a large pig, unlikely to have been reduced much in size from its wild progenitor (Table 10.1). No example of LEH was recorded in any of the teeth.

A total of 68 caprine fragments were recorded from Anaro. Only the domestic goat, Capra hircus, was ever introduced to the Batanes Islands. All remains positively identified as caprines (including sheep as well as goats) are taken to be goat. Sheep were introduced to the Philippines, but only in the recent past. The fragments consisted primarily of loose teeth or tooth fragments $(\mathrm{N}=48)$, and a few cranial and post-cranial elements. Goat was identified in all trenches except Anaro 6. In Anaro 3, goat was primarily recovered from the upper $50 \mathrm{~cm}$, with just four fragments in Trenches $3 \mathrm{D}(\mathrm{N}=2)$ and $3 \mathrm{G}(\mathrm{N}=2)$ at $60-70 \mathrm{~cm}$.

Most of the molars demonstrate extensive wear indicating that the majority of animals were mature adults at the time of death (Table 10.8). Hillson (2005) noted that there is a considerable variation in the eruption timing of the teeth of different domestic goat breeds. But the presence of worn third molars suggests individuals older than 24 months (Moran and O'Connor 1994). A left mandibular dp 4 from $1 \mathrm{~B}(10-20 \mathrm{~cm})$, a fragment of left mandible containing a dp2 from 3B $(30-40 \mathrm{~cm})$, and an unworn upper left first molar and unfused distal epiphysis from a metapodial from $3 \mathrm{E}(30-40 \mathrm{~cm})$ suggest that some individuals also died before they reached maturity. 


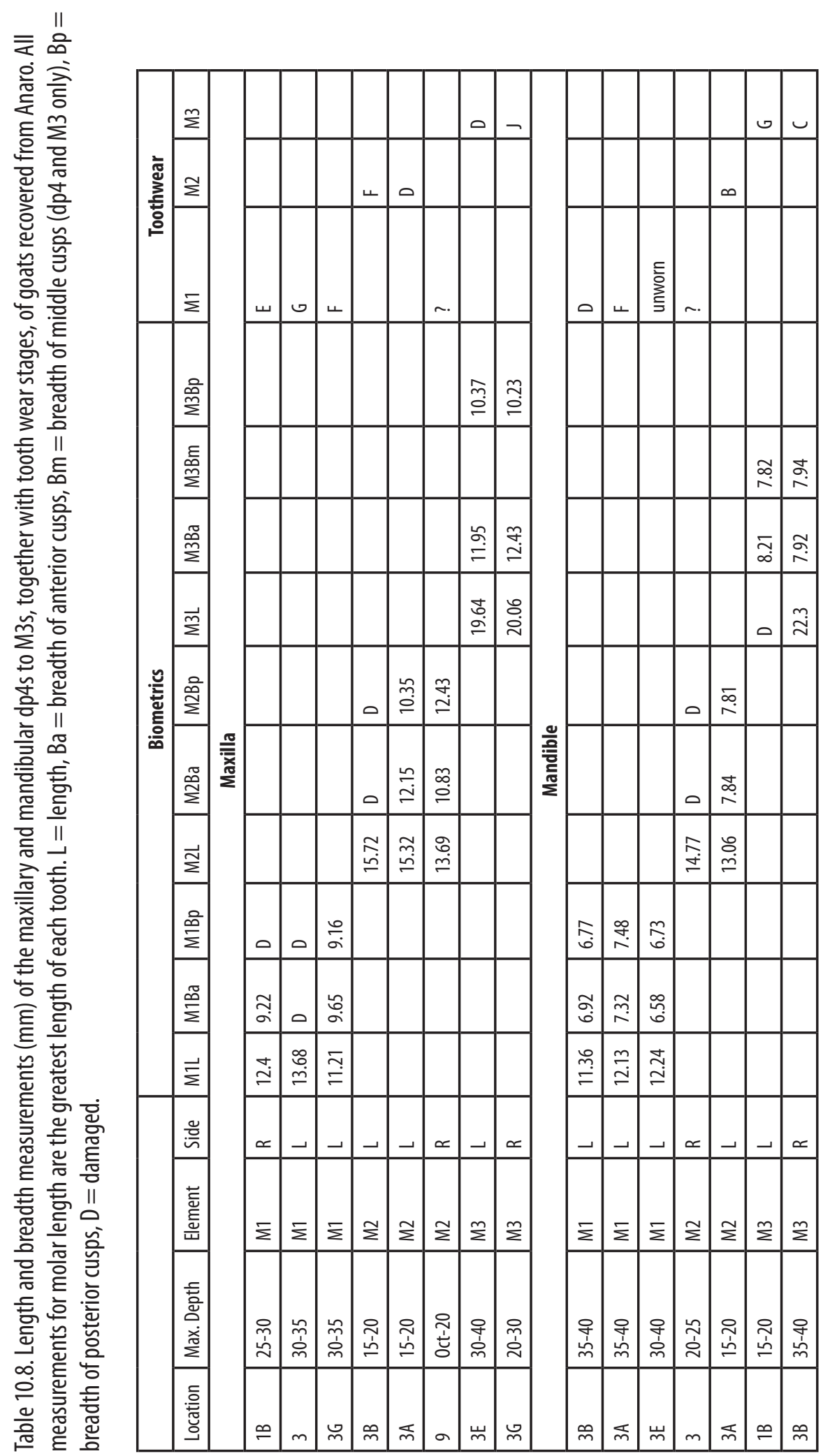


Table 10.9. A comparison of the mandibular tooth row lengths $(\mathrm{mm})$ from the cranial end of the canine alveolus to the caudal margins of the M2 of the viverrid archaeological specimen from Anaro $6(80-90 \mathrm{~cm})$ and a number of Paguma larvata (subsp.) and Paradoxurus hermaphroditus specimens held within the mammal section of Naturalis, Leiden, and the zooarchaeology laboratory, Archaeological Studies Program (ASP), University of the Philippines; all taxonomic nomenclature follows the original labels for museum specimens.

\begin{tabular}{|l|l|l|l|}
\hline Species & Sex & Facility/ Accession No. & Tooth row length (mm) \\
\hline Archaeological specimen & I & Anaro 6 (80-90 cm) & 37.66 \\
\hline Paguma larvata taivana (Taiwan) & F & Mammal Sec. Naturalis 20861 & 39.24 \\
\hline Paguma larvata taivana (Taiwan) & F & Mammal Sec. Naturalis 20860 & 39.55 \\
\hline Paguma larvata taivana (Taiwan) & M & Mammal Sec. Naturalis 20911 & 34.87 \\
\hline Paguma larvata (Borne0) & F & Mammal Sec. Naturalis 34668 & 45.93 \\
\hline Paguma larvata leucomystax (Sumatra) & F & Mammal Sec. Naturalis 14672 & 50.57 \\
\hline Paguma larvata leucomystax (Sumatra) & F & Mammal Sec. Naturalis 15750 & 52.46 \\
\hline Paguma larvata leucomystax (Sumatra) & M & Mammal Sec. Naturalis 1370 & 50.61 \\
\hline Paguma larvata leucomystax (Sumatra) & F & Mammal Sec. Naturalis 20778 & 48.45 \\
\hline Paradoxurus hermaphroditus (Brunei) & I & Mammal Sec. Naturalis 20765 & 41.66 \\
\hline Paradoxurus hermaphroditus (Sumatra) & I & Mammal Sec. Naturalis 324 & 42.37 \\
\hline Paradoxurus hermaphroditus (Sumatra) & F & Mammal Sec. Naturalis 34681 & 41.96 \\
\hline Paradoxurus hermaphroditus (Sumatra) & M & Mammal Sec. Naturalis 20312 & 43.63 \\
\hline Paradoxurus philippinensis (Philippines) & M & Mammal Sec. Naturalis 34737 & 42.48 \\
\hline Paradoxurus hermaphroditus (Palawan) & I & Zooarchaeology Lab. ASP A0095 & 38.43 \\
\hline Paradoxurus hermaphroditus (Palawan) & I & Zooarchaeology Lab. ASP A0044 & 44.65 \\
\hline
\end{tabular}

Body part representation is difficult to assess from the few fragments recorded at Anaro, but several meat-yielding elements such as the humerus and scapula are represented, as well as teeth and skulls (Fig. 10.5). Some small fragments of vertebrae and rib within the upper $50 \mathrm{~cm}$ of Anaro 3 that could only be identified as 'large mammal' might be parts of caprines, as well as pigs.

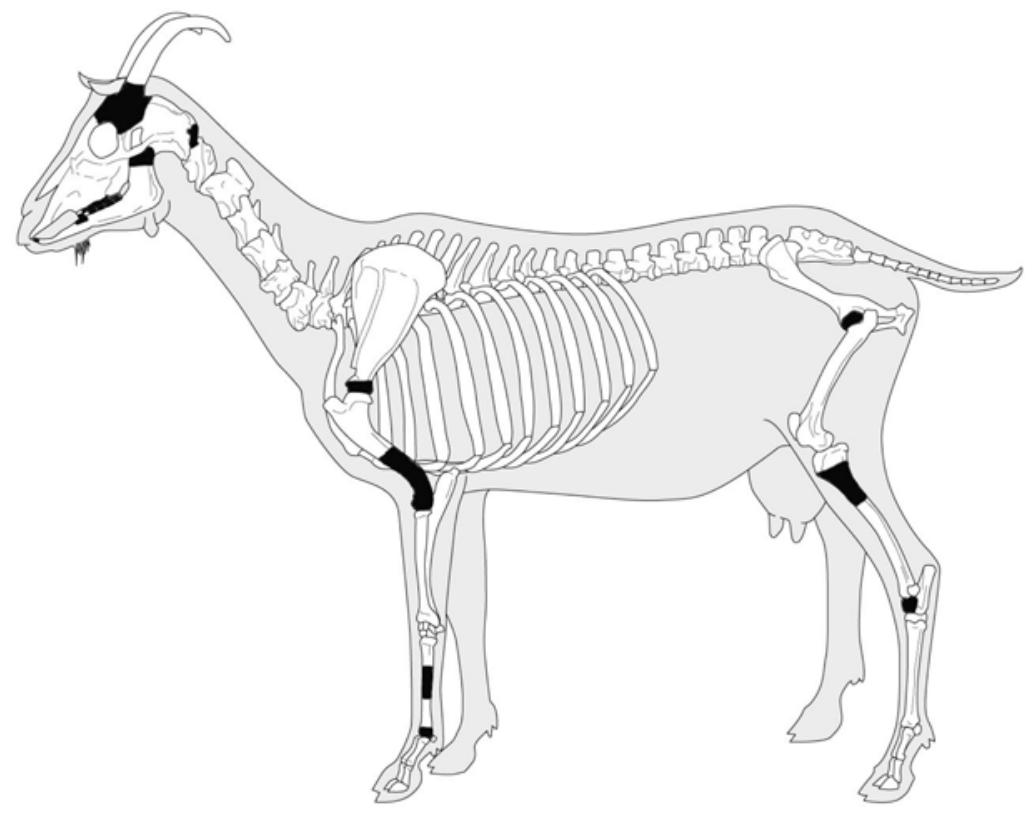

Figure 10.5. The goat body part representation (shaded) from Anaro. 


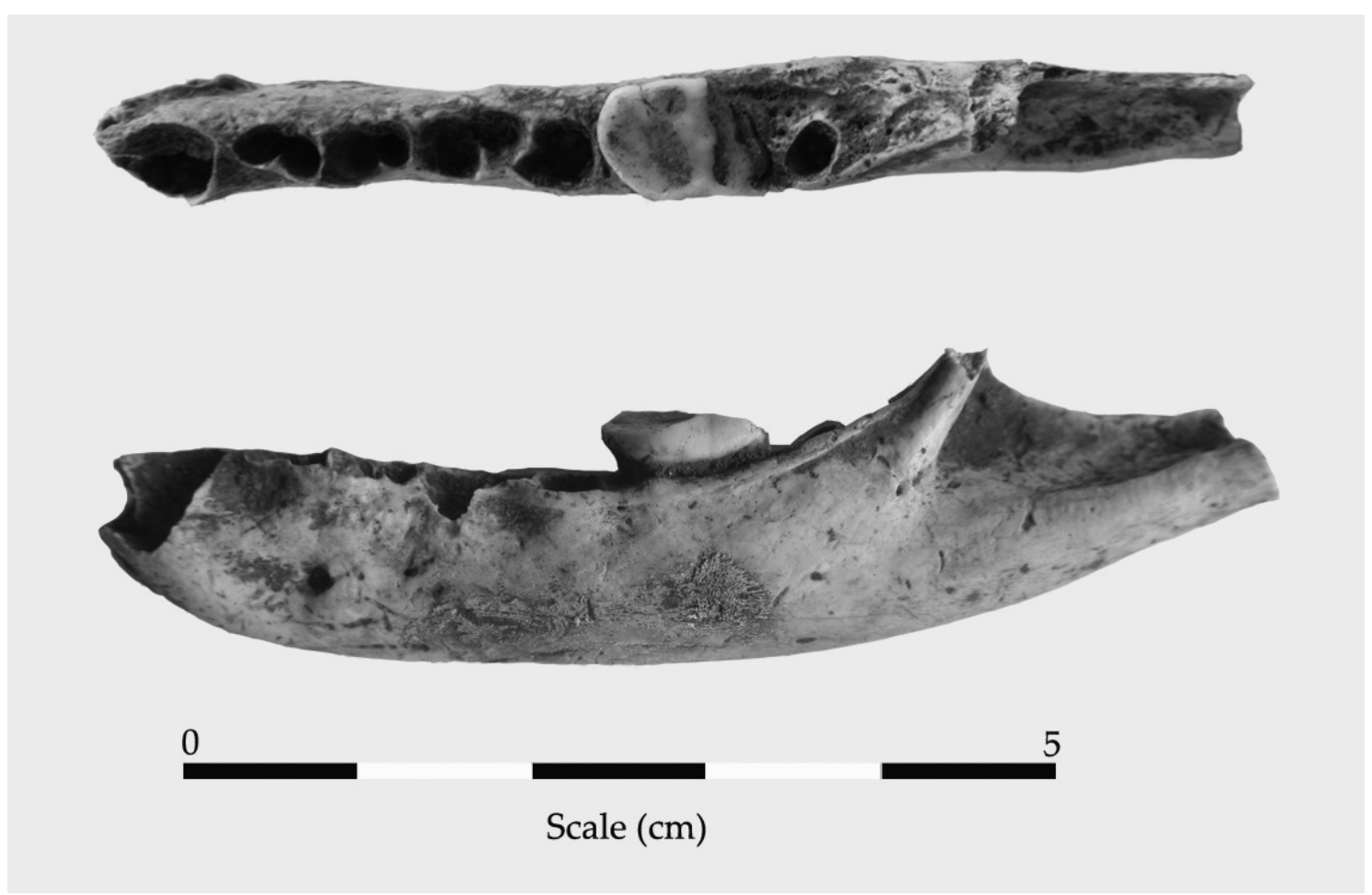

Figure 10.6. The occlusal (above) and labial (below) aspects of the viverrid left mandible from Anaro $6(80-90 \mathrm{~cm})$.

Source: Philip Piper.

The lengths and breadths of caprine molars overlap with those recorded from $14^{\text {th }}-17^{\text {th }}$ century AD East Timor (Amano and Piper 2011). Indeed, measurements were not significantly different from those taken on modern domestic goats housed at the University of the Philippines, Archaeological Studies Program.

The bones of a viverrid also occur in small numbers $(\mathrm{N}=8)$ throughout the Anaro archaeological sequence, with the earliest occurrence possibly recorded in Anaro 6 at 110-120 cm. One mandible from Anaro $6(80-90 \mathrm{~cm})$ consisted of a complete mandibular body, from the cranial aspects of the canine alveolus to the ventral portions of the mandibular ramus. It still contained a first molar (Fig. 10.6), so heavily worn that it has completely lost its crown morphology and caudal portions. The specimen was taken to the Natural History Museum (Naturalis) in Leiden, Netherlands, for comparison with the two most likely species to be represented, the common palm civet (Paradoxurus hermaphroditus) and the masked palm civet (Paguma larvata). Attempts at differentiation using tooth morphology and the locations and alignments of the empty alveoli were inconclusive. Measurements of the mandibular length from the cranial end of the canine alveolus to the caudal margins of the second molar alveolus indicates that the specimen falls within the range of Paguma larvata taivana, the small Taiwanese subspecies of masked palm civet, but is also comparable in size to the small sample of modern comparative specimens of common palm civet held within the zooarchaeology collection, Archaeological Studies Program, University of the Philippines (Table 10.9). Taxonomic identification will need to await recovery of fragments with more diagnostic features (see below). A left humerus from Anaro 3A $(45-50 \mathrm{~cm})$ with an unfused distal articular end indicates the presence of sub-adults and suggests that Itbayat was home to a breeding population of civet cats. A small right calcaneus from the subsurface in Anaro 7 could indicate that civet populations, that are unknown on the island now, survived until relatively recently. 
Seven bird bones were recorded from Anaro, none of similar size or morphology to the chicken skeleton. A fragment of proximal right tibiotarsus from Anaro 3F $(40-50 \mathrm{~cm})$ bears an oblique cut mark on its postero-lateral surface, close to the articular end, indicating that this specimen was butchered and consumed. Three indeterminate snake vertebrae were recovered from Anaro $1 \mathrm{~B}(25-30 \mathrm{~cm}$ and $40-45 \mathrm{~cm})$ and $2 \mathrm{~A}(10-15 \mathrm{~cm})$.

\section{Bone artefacts from Anaro}

Two complete and five fragments of bone and tooth artefact were recovered from Anaro, as well as a waste fragment from artefact production. A male pig lower canine from Anaro 3C (60-65 $\mathrm{cm}$ ) was deliberately split longitudinally (length $39.21 \mathrm{~mm}$, maximum width $7.06 \mathrm{~mm}$ ), and its occlusal surface ground down to remove rough edges (see Fig. $8.11 \mathrm{~K}$ ). A transverse notch was ground out on the same split side of the specimen for the secure attachment of a cord or line. This specimen was probably used as a fishing gorge.

Another fragment of bone from Anaro 3A $(80-90 \mathrm{~cm})$ has been roughly ground on all surfaces to form a circular profile and to taper into a point at either end. The specimen is $35.25 \mathrm{~mm}$ in length and has a maximum width of $2.69 \mathrm{~mm}$. It was probably also a fishing gorge (Fig. 10.7).

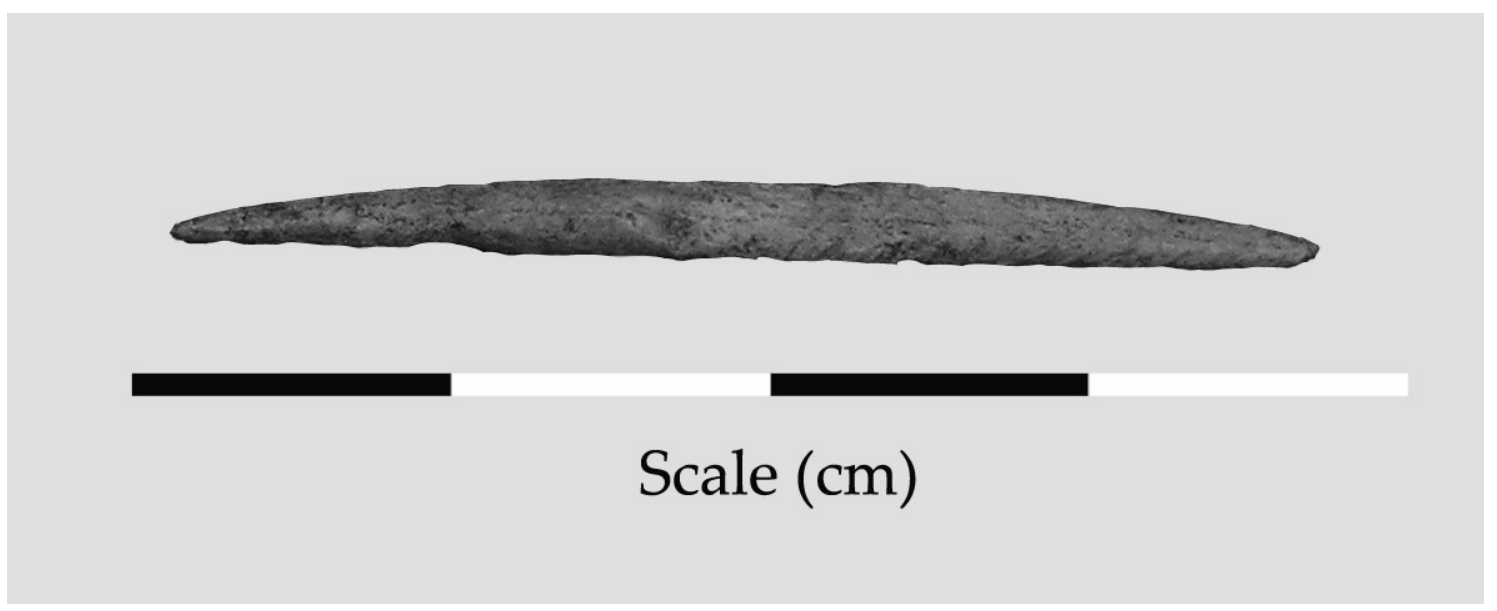

Figure 10.7. A probable fishing gorge from Anaro $3 \mathrm{~A}(80-90 \mathrm{~cm})$.

Source: Philip Piper.

Two fragments of bone from Anaro $3(70-75$ and $80-85 \mathrm{~cm}$ ) have diameters of $3.37 \mathrm{~mm}$ and 1.9 $\mathrm{mm}$ respectively, suggesting they are from two different artefacts (fragment lengths $=39.39 \mathrm{~mm}$ and $17.49 \mathrm{~mm}$ respectively). Both are split transversely, but it is clear they have been ground on all surfaces to produce a circular profile and to taper to a point. There is no evidence of a notch on either specimen, but microscopic analysis of the tip indicates no rotational wear that would suggest use as awls. It is possible that both are broken fishing gorges or projectile points.

A fragment of male pig left lower canine, $56.57 \mathrm{~mm}$ in length and $11.27 \mathrm{~mm}$ in maximum width has a transverse fracture at the cranial end and longitudinal break towards the caudal end. The occlusal surface has regular transverse striations and grooves that appear to be too deep and regular and cover too much of the surface to reflect the natural wear caused by the pig upper and lower canines when they grind against each other. It is possible that this fragment of canine was used as some sort of scraping or planing tool for materials such as wood. Similar tools were recently recorded by Piper et al. (2010) from the Neolithic site of An Son in southern Vietnam. One of these examples had resin adhering to the labial and lingual surfaces close to the caudal end of the tooth, indicating it had almost certainly been hafted. 


\section{Torongan Cave: Taxonomy}

Of the 121 bone fragments from Torongan, 96 (79.3\%) were recovered from within the upper $30 \mathrm{~cm}$ of the excavation. The upper $5 \mathrm{~cm}$ consisted primarily of bone fairly recently introduced to the site, including one human hand phalanx and one toe phalanx. Three domestic animals are represented within the archaeological record, the pig $(\mathrm{NISP}=4)$, goat $(\mathrm{NISP}=8)$, and as a surface find a fragment of bovine metacarpal. The goat remains are all restricted to the upper 25 $\mathrm{cm}$ of deposit, whereas one of the four pig fragments was recovered from a depth of $55 \mathrm{~cm}$. This would suggest that there is some stratigraphic and chronological integrity, with the upper $25 \mathrm{~cm}$ at Torongan post-dating the introduction of goats to Itbayat, and the lower deposits pre-dating it.

The assemblage also includes four Viverridae fragments, including a femur and humerus, all from the upper $25 \mathrm{~cm}$. The distal end of the humerus has unfused epiphyses, which suggest that breeding populations of this taxon inhabited the surroundings of Torongan Cave. In addition, a rib and vertebra of a small snake species were recovered from $30 \mathrm{~cm}$ and $50 \mathrm{~cm}$ respectively.

Below $45 \mathrm{~cm}$ depth, and with the exception of two very small and severely eroded pig tusk fragments, the Torongan bone assemblage consisted entirely of rat and bat bones. The excellent condition of the small vertebrate remains suggests that, if anthropic derived midden bone had been deposited on the site, it would still be represented. Thus, the taphonomic heterogeneity of vertebrate remains suggests that at least the lower $25 \mathrm{~cm}$ of deposit represents nothing more than reworking and redeposition of waterborne deposits, intermixed with some cultural material, as suggested by the geomorphological and archaeological interpretations for the site (chapter 2).

\section{Savidug Dune Site: Taxonomy}

In total, 291 specimens (24\%) of the terrestrial animal bone assemblage (including marine turtles) could be identified to class or higher taxonomic level. Of these, 279 could be securely placed within layers 2, 4 and 5. The most common taxon was the pig, accounting for 234 (80.4\%) of the identified bones. It is probably safe to conclude that the majority, if not all, of the unidentified 'large mammal' bone fragments are from pigs (Table 10.10).

Just 11 bone fragments in layer 5 could be identified to taxon, including a fragment of pig lumbar vertebra, a complete right 2 nd metatarsal, and a fragment of left 3 rd metacarpal. Another eight were severely weathered and abraded pieces of marine turtle carapace and/or plastron and ribs.

\section{Savidug Dune Site layer 4}

Seventy-five pig bones could be securely provenanced to layer 4, with at least four individuals represented, based on left maxillary fragments. The small number of pig mandibles and maxillae $(\mathrm{NISP}=6)$ with teeth are all from adult individuals, with at least three of the specimens exceeding three years of age at the time of death (Bull and Payne 1982). These include the fused right distal tibia in R7-9 (110-120 cm) from an individual greater than 18 months of age, and two axial metapodials with fused distal ends from a pig in excess of two years old (Bull and Payne 1982). A fused distal articular end of a left humerus in C10 $(100-110 \mathrm{~cm})$ belonged to an animal in excess of one year old, but this is likely to belong to cultural layer 2 .

There is little that can be said from the few mandibular and maxillary teeth recovered from this phase, except that the teeth are relatively large and fall within the expected size range for the comparative examples of Sus scrofa from Taiwan and China (Table 10.11).

Many of the high meat-yielding bones from pigs, such as the scapula, humerus and pelvis were recorded, as well as loose teeth and extremities. This suggests that most elements in the skeleton are represented in the archaeological record (Fig. 10.8). 


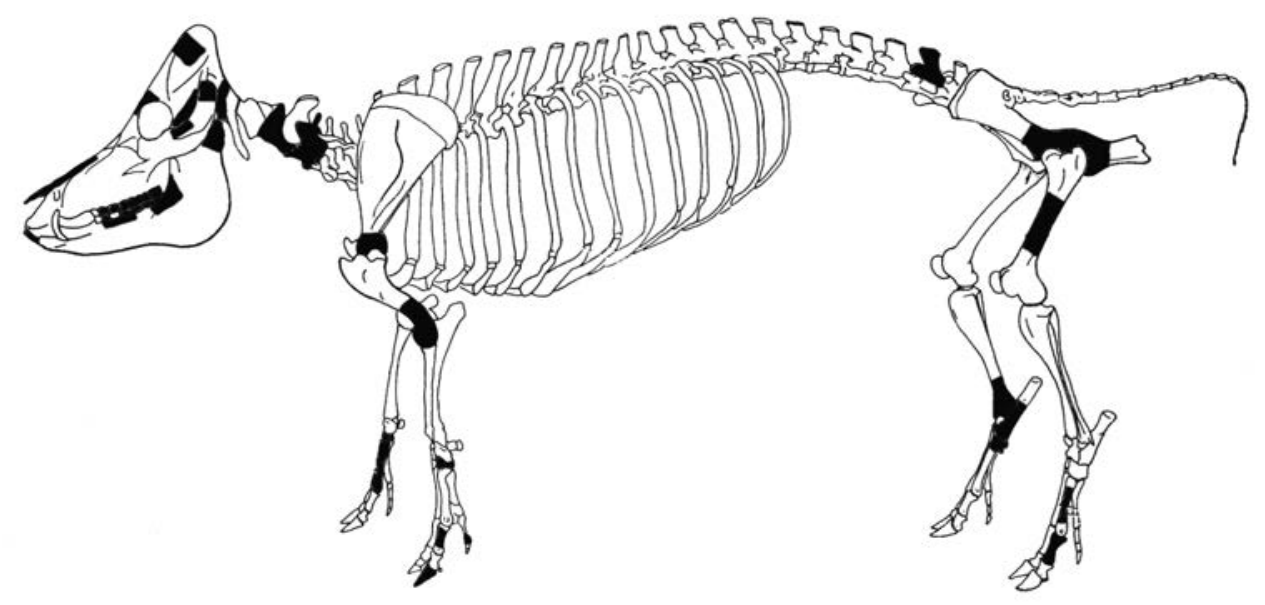

Figure 10.8. The pig body part representation (shaded) from Savidug Dune Site layer 4.

Source: Philip Piper.

Three fragments of dog were recorded in QR 7-9 layer 4, a basioccipital at 120-130 cm and the proximal end of a right scapula at $110-120 \mathrm{~cm}$ (Fig. 10.9). A fragment of right mandibular condyle from 110-120 cm, also from a dog, has eight transverse cut marks on the labial margins of the neck of the mandibular condyle, suggesting that this individual was possibly butchered for consumption, or perhaps the skull or mandible was removed as a trophy or for display (Fig. 10.10).

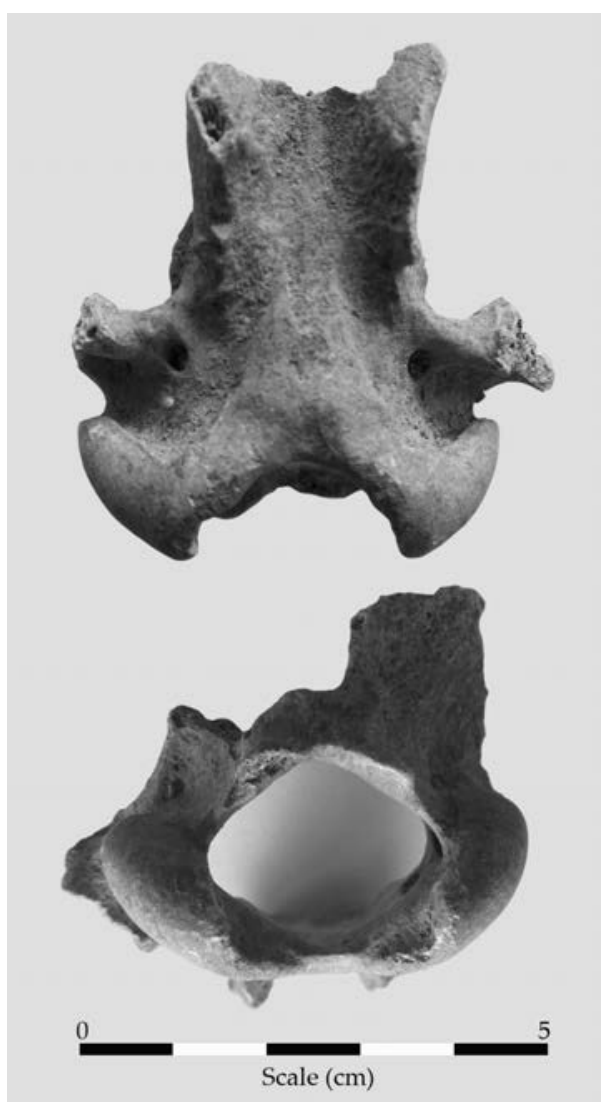

Figure 10.9. The ventral (above) and caudal (below) aspects of a dog basioccipital from Savidug Dune Site QR 7-9, $120-130 \mathrm{~cm}$.

Source: Philip Piper. 


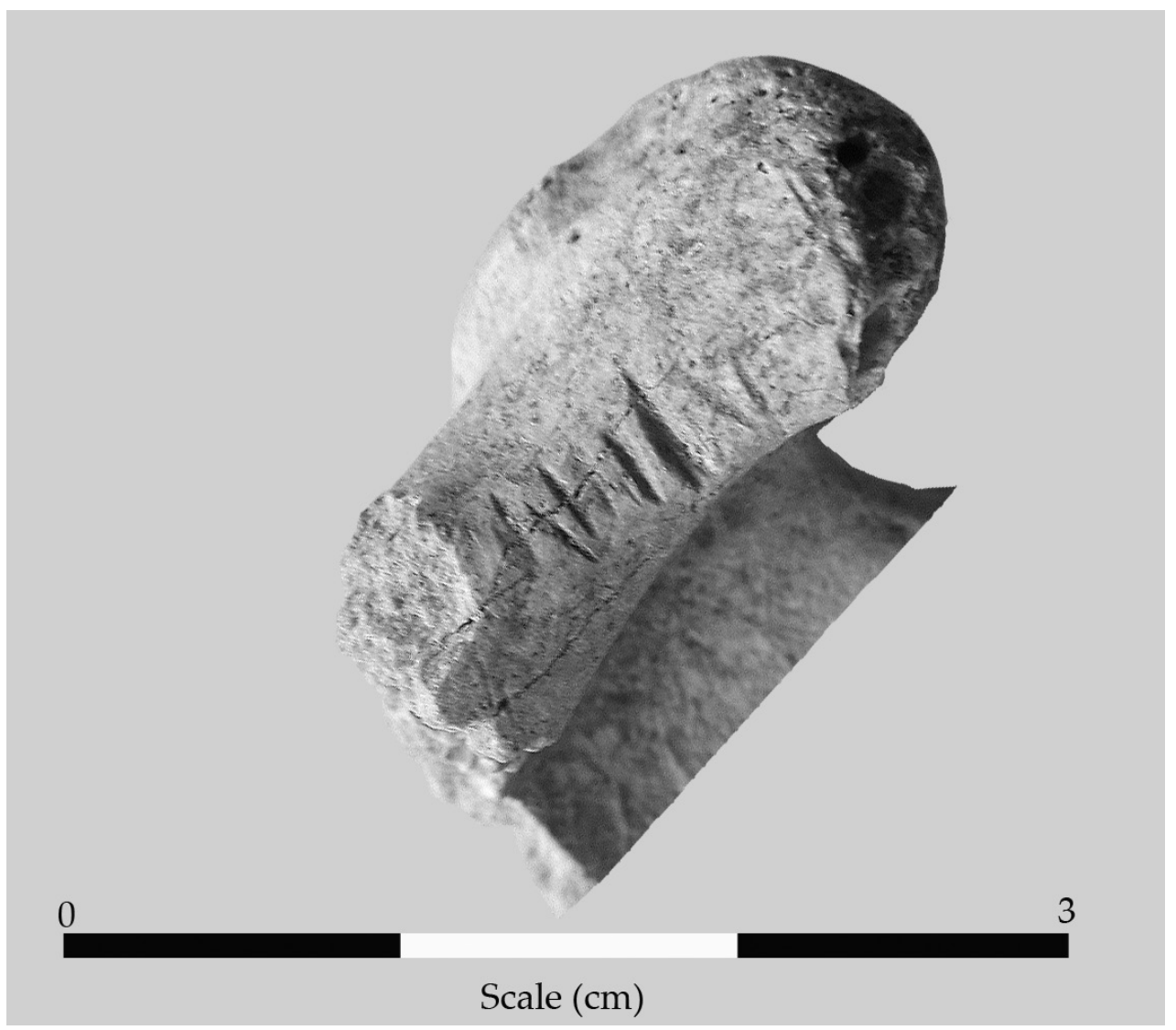

Figure 10.10. A dog right mandibular condyle from Savidug Dune Site QR 7-9, 110-120 cm, with eight transverse cut marks on the neck (in approximate anatomical position).

Source: Philip Piper.

Table 10.10. The number of identified specimens (NISP) from layers 2, 4 and 5 in Savidug Dune Site.

\begin{tabular}{|l|l|l|l|l|l|}
\hline Class & Taxon & Layer 2 & Layer 4 & Layer 5 & Total NISP \\
\hline Reptilia & Testudine & 1 & 16 & 8 & 25 \\
\hline Aves & Bird indet. & 3 & 5 & 0 & 8 \\
\hline Mammalia & Rat-sized murid & 6 & 0 & 0 & 6 \\
\hline & Rattus sp. & 1 & 0 & 0 & 1 \\
\hline & Canis familiaris & 0 & 3 & 0 & 3 \\
\hline & Sus scrofa (domestic) & 129 & 102 & 3 & 134 \\
\hline & Cervid indet. & 2 & 0 & 0 & 2 \\
\hline & TOTAL & $\mathbf{1 4 2}$ & $\mathbf{1 2 6}$ & $\mathbf{1 1}$ & $\mathbf{1 7 9}$ \\
\hline
\end{tabular}



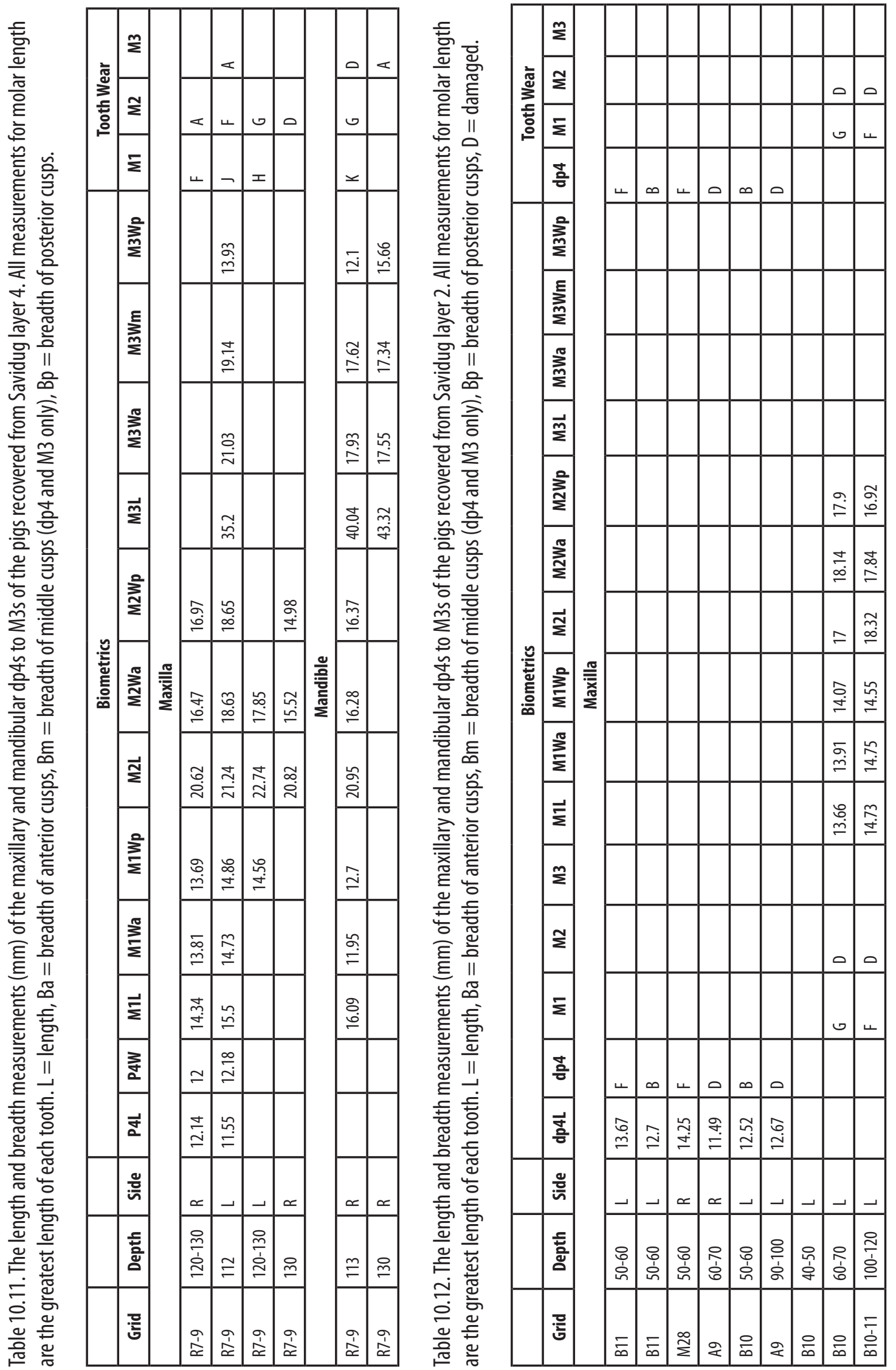


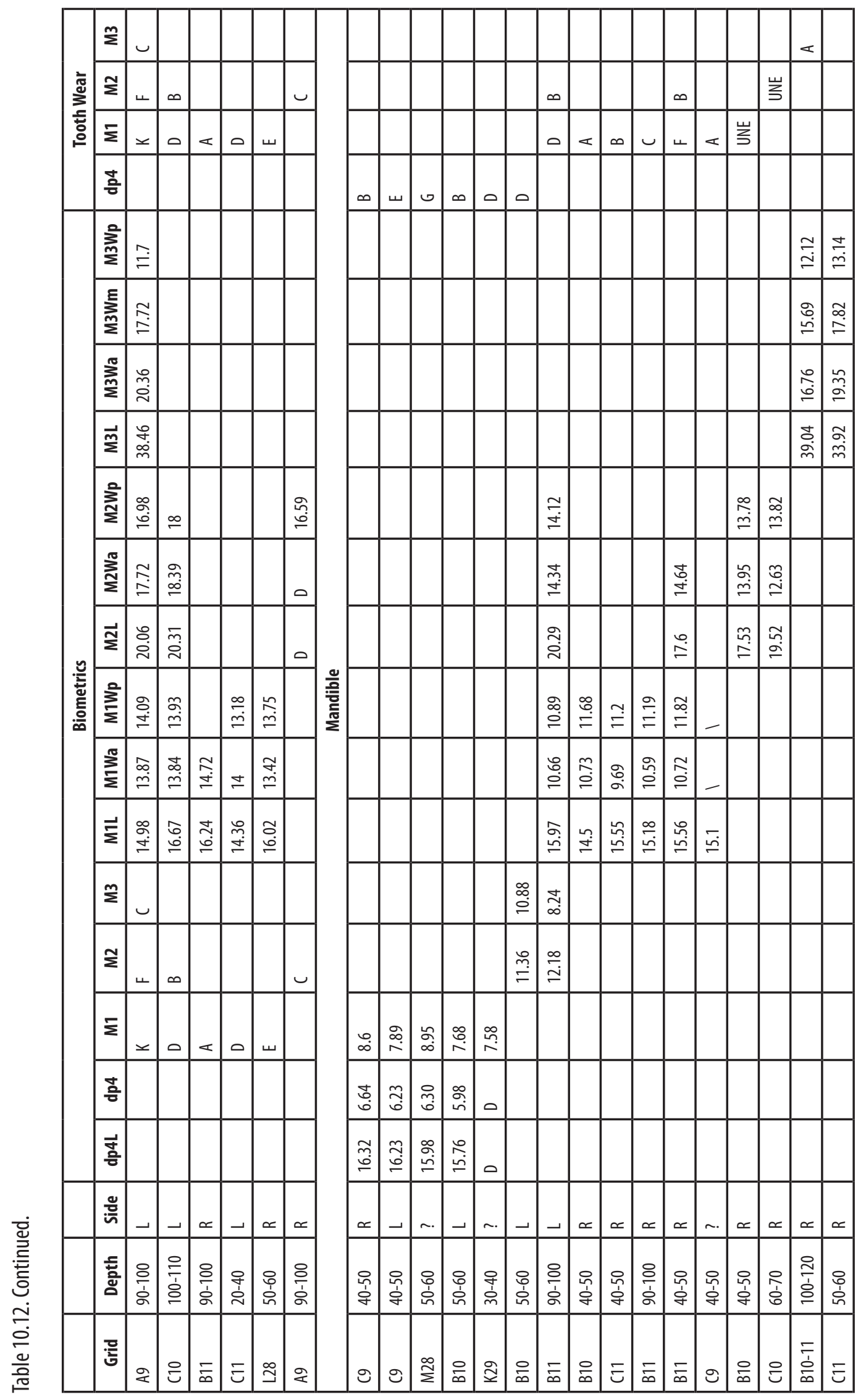


The proximal end and shaft of a murid right femur from QR 7-9 $(120-130 \mathrm{~cm})$ is somewhat distinctive. The element is smaller than expected for a rat-sized murid, although the proximal diaphysis is unfused and could potentially have been a sub-adult. The dorsal margins of the greater trochanter and the whole of the lesser trochanter are missing. There is a noticeable medialorientated curvature in the shaft below the neck. The $3^{\text {rd }}$ trochanter is broad and merges with the ventral margins of the greater trochanter. The $3^{\text {rd }}$ trochanter is also more developed and distinct than in commensal murids (including mice) and extends further down the femoral shaft. This is potentially a fragment of femur from a native (endemic) murid species, rather than an introduced one.

Five small fragments of bird long bone and a possible coracoid were recorded in QR 7-9 at depths between 120 and $150 \mathrm{~cm}$. A single, small fragment of right tibiotarsus shaft with the dorsal portion of the extensor canal underneath the supratendinal bridge is remarkably similar in both size and morphology to three comparative specimens of chicken (Gallus gallus) held in the Archaeological Studies Program, Zooarchaeology Laboratory, University of the Philippines. This specimen was recorded in $\mathrm{Q} / \mathrm{R} 7-9$ at $110-120 \mathrm{~cm}$ and thus dates to $c .500-300 \mathrm{BC}$ (Fig. 10.11). Fifteen severely weathered and abraded fragments of turtle carapace and/or plastron were also recovered from layer 4.

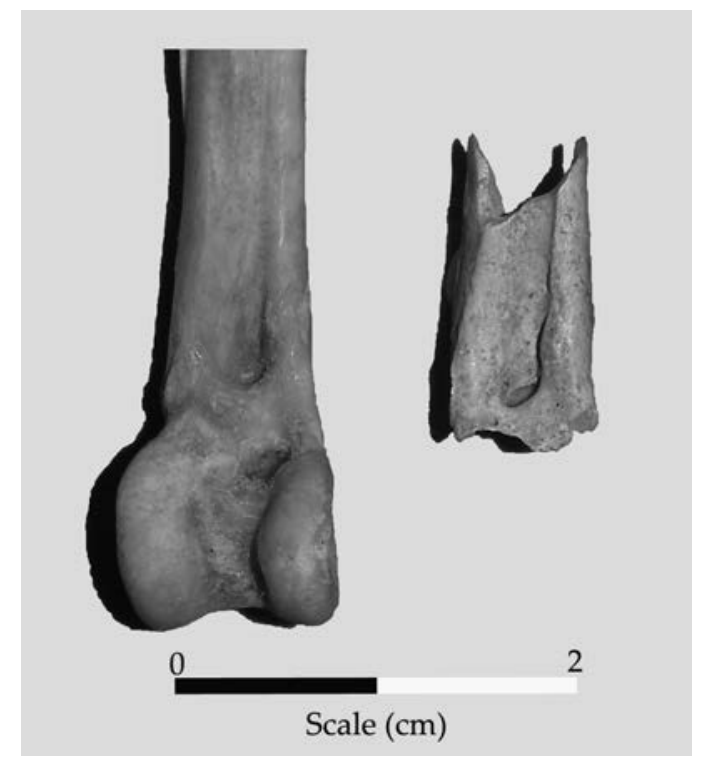

Figure 10.11. A fragment of right tibiotarsus shaft from Savidug Dune Site $Q / R 7-9,110-120 \mathrm{~cm}$, with the dorsal portion of the extensor canal underneath the supratendinal bridge (right). This is remarkably similar in both size and morphology to three comparative specimens of chicken (Gallus gallus) held in the University of the Philippines Archaeological Studies Program, Zooarchaeology Laboratory (left).

Source: Philip Piper.

\section{Savidug Dune Site layer 2}

Layer 2 produced 156 identifiable fragments of pig. Based on upper left first molars, at least five individuals are represented (Table 10.12). There is a relatively high proportion of $\mathrm{dp} 4 \mathrm{~s}$ in the assemblage $(\mathrm{N}=14)$ from at least four individuals. All retain their roots, indicating that they were not shed naturally but represent animals killed at or below 12-18 months of age. The maxillary and mandibular first and second molars demonstrate a range of ages at death from unerupted to moderately worn, but none shows the advanced Grant wear stages associated with considerable 
age. Only one of the three recovered M3s demonstrates any kind of occlusal wear (Grant Stage C) and comes from a slightly older individual than the majority of the assemblage. No LEH was recorded in any of the teeth.

The conclusion reached from the dental remains that pigs were killed at a young age is supported by the presence of right and left unfused innominates from juvenile individuals in B9 (60-70 $\mathrm{cm})$, C9 $(40-50 \mathrm{~cm})$ and C10 $(40-60 \mathrm{~cm})$. A humeral shaft fragment with unfused distal end in C9 $(30-40 \mathrm{~cm})$ is from a pig less than one year old.

Body part representation is hard to ascertain from the small number of identifiable fragments, but both high meat-yielding bones such as the humerus, femur and pelvis are all represented as well as parts of the skull, loose teeth and extremities, suggesting all parts of the pig skeleton were entering the archaeological record (Fig. 10.12).

In addition to the pig bones, three bird bones including a humeral shaft fragment of a 'chickensized' bird $(\mathrm{A} 10,20-40 \mathrm{~cm})$ and several rat-sized murid bones were also identified in layer 2. A rat left mandible from N27 $(20-30 \mathrm{~cm})$ has a first molar with the antero-lingual cusp much larger than the antero-labial, and when viewed from above is centrally placed in the anterolobus. The antero-labial cusp is offset and located slightly posteriorly of the antero-lingual cusp. As a result, the metaconid and entoconid have a steeper slope towards the posterior than the protoconid and hypoconid. The posterior cingulum is relatively large. A small cusplet on the anterolabial side of the protoconid is present. This distinctive tooth morpohology places this specimen within the genus Rattus.

Intriguingly, a heavily worn deer right lower second molar was recovered from L27 $(0-20 \mathrm{~cm})$. The cranial end of the tooth is missing and it is worn almost to the pulp cavity, but is still distinctively that of a cervid (Fig. 10.13). The tip of a deer antler tine was also identified in C10 at $100-110 \mathrm{~cm}$. There is no indication that this specimen was curated in any way that would suggest import from elsewhere and use either as a tool or a decorative piece. This raises the possibility that a deer species was once present on Savidug. A single fragment of marine turtle plastron was identified in M27 (40-50 cm).

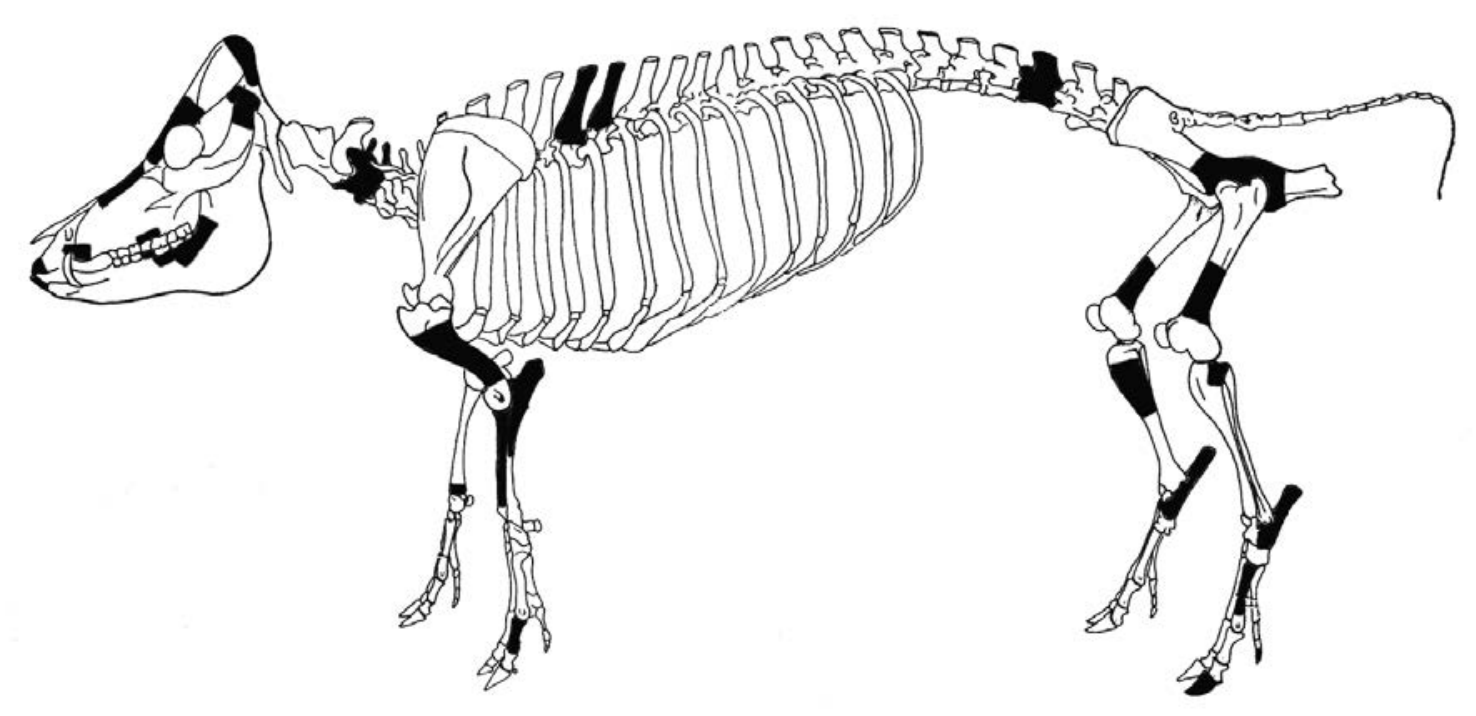

Figure 10.12. The pig body part representation (shaded) from Savidug Dune Site layer 2. 


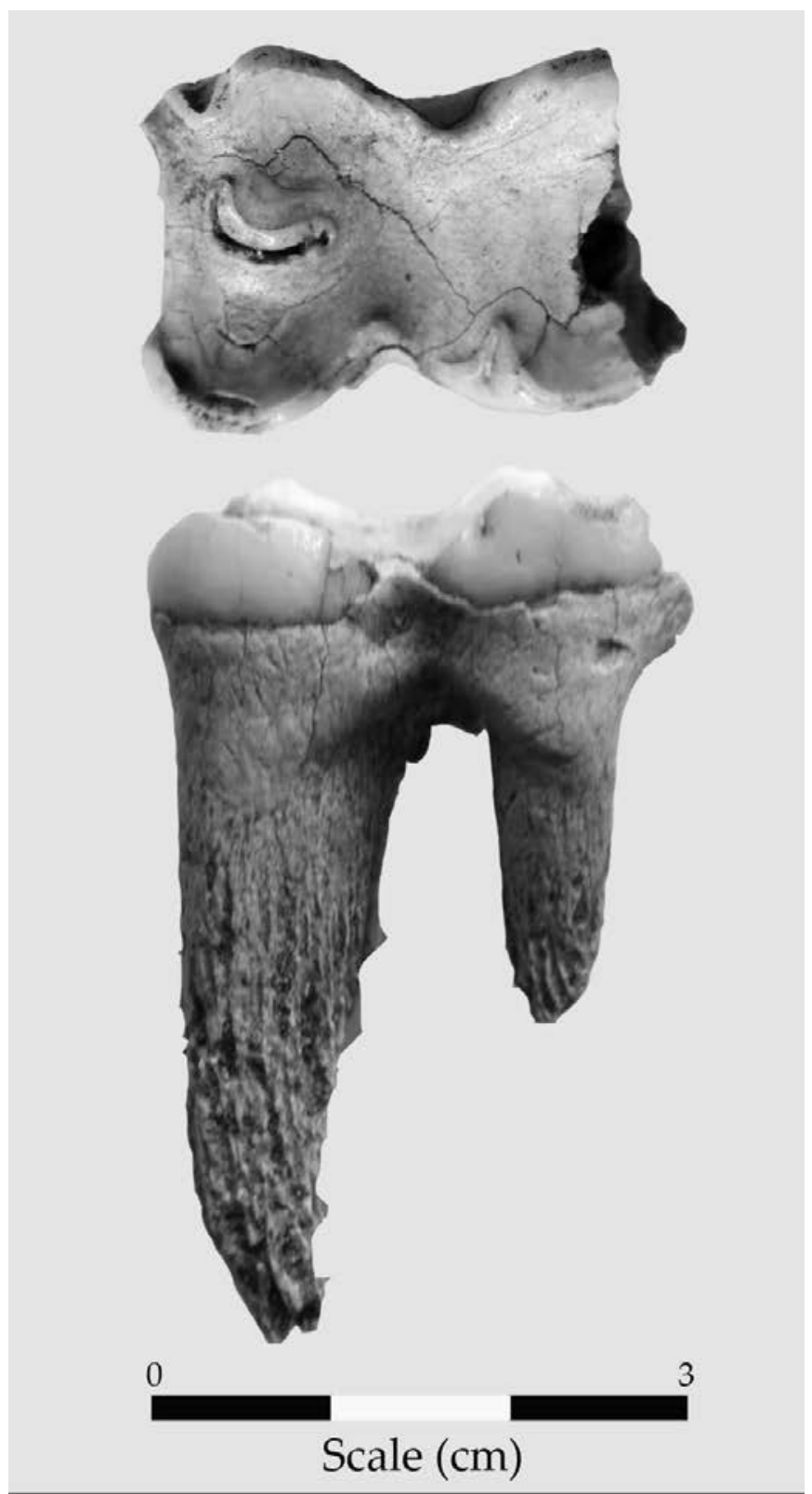

Figure 10.13. The labial (below) and occlusal (above) aspects of the heavily worn cervid right lower $2^{\text {nd }}$ molar recovered from Savidug Dune Site L27 at 0-20 cm.

Source: Philip Piper.

\section{Pamayan: Taxonomy}

The most common mammal remains recorded in Pamayan are goat $(\mathrm{N}=50)$, with bones recovered throughout the sequence from near the base at $100-105 \mathrm{~cm}$ to the sub-surface. This indicates that the Pamayan shell midden developed after the introduction of the goat to the Batanes Islands.

Goats appear to have been killed at a variety of ages at Pamayan. Only a single dp4 was recovered, from $85-90 \mathrm{~cm}$, and most of the molars are moderately to heavily worn suggesting they are from mature individuals. The assemblage contains an unworn maxillary second molar from $75-80 \mathrm{~cm}$, an unfused right innominate from $100-105 \mathrm{~cm}$, and an unfused lumbar vertebra centrum and neural arch from $95-100 \mathrm{~cm}$. 
The pig is represented by 33 fragments distributed throughout the archaeological sequence, from the base at 100-105 cm to within the upper $15 \mathrm{~cm}$. It is difficult to build an age profile from the fragmentary remains but there are at least two juvenile pigs, based on the presence of two upper left dp2s. There is a left upper dp2 from 30-35 cm, an unerupted second molar at 40-45 $\mathrm{cm}$ still the process of development and with no root formation, a sub-adult calcaneus at 50-55 $\mathrm{cm}$, and an unfused right ilium at $70-75 \mathrm{~cm}$. At least one adult is also represented by a right $2 \mathrm{nd}$ metacarpal with fused distal epiphyses at $70-75 \mathrm{~cm}$.

A single murid right femur, a small weathered piece of turtle plastron and 14 indeterminate bird bone fragments were also identified in the assemblage. None of the bird bones approximated the chicken in size.

Finally, a small fragment of turtle carapace or plastron $15.65 \mathrm{~mm}$ in length, with a maximum width of $8.36 \mathrm{~mm}$ and thickness $4.26 \mathrm{~mm}$, retains part of a cut and shaped rounded end. On one side the cortical bone remains, on the other the cancellous bone has been ground flat to produce the desired thickness. The function of this small fragment of artefact is unknown.

\section{Discussion and conclusions}

In the earliest phases of site occupation (layer 5) in Savidug Dune Site the only identifiable nonfish vertebrate remains are those of the pig (Sus scrofa) and marine turtle. This suggests that pigs were present on Sabtang by at least 1200 BC. A pig bone from Torongan Cave was recovered from a similar depth $(50-55 \mathrm{~cm})$ as a fragment of Turbo shell dated to $1384-1095 \mathrm{cal}$. BC (WK 14641), and could indicate that suids were introduced to Itbayat even earlier. Analyses of the pig teeth from the Batanes Islands indicates that all specimens are similar in size and morphology to those of the Eurasian boar Sus scrofa from China and Taiwan and fall outside those expected for the Philippine warty pigs (S. philippensis and S. cebifrons). These species, endemic to the Philippine archipelago, have a distinctive tooth morphology and small size (reflected in the size of the teeth) that makes them easily distinguishable from introduced domestic pigs in the zooarchaeological record (see Amano et al. in press for discussion).

It is known that pigs were probably introduced to Lanyu Island, between the Batanes Islands and Taiwan, long enough ago to become a genetically distinctive island native population (Wu et al. 2007). These Lanyu pigs are closely related to East Asian Sus scrofa, from which they derive. However, there is no evidence of a human presence on the Batanes Islands prior to the Neolithic and it is likely that pigs were translocated to these islands during this period. There are too few pig remains to reach any solid conclusion about management strategies in the earliest Phase 4 assemblages. During the proto-historic period there appears to have been a preference towards slaughtering sub-adults and young adults within the first year or two of life.

At Anaro, the remains of several neonatal pigs were also recovered. In modern pig populations nearly $80 \%$ of pre-weaning mortality occurs within the first three days after birth (Svendsen 1982), and approaches $60 \%$ in free-ranging 'feral' pigs (Barber and Coblenz 1986). If pigs had been free-ranging around the Anaro site then neonates would have been deposited at farrowing sites, locations where the sows chose to give birth. It is highly unlikely that these casualties would have entered the archaeological record, as farrowing sites would be away from human disturbance, if sows had that choice. Thus, the presence of neonates in the archaeological record during this phase of occupation could be an indication that, whilst Anaro was occupied, pig populations were stalled in and around the human habitations. In this regard, Jirobei (in Yamada 2007: 326) recounts a late $17^{\text {th }}$ century battle between two chiefdoms on Batan Island in which several hundred people were killed. Inter-community violence and theft during this late period of prehistory might have encouraged communities to corral pigs within settlements, rather than 
allowing them to range freely as they perhaps had done in the past. In more practical terms, there may have simply been a need a restrain pigs from causing damage by rooting through valuable food gardens.

At Anaro 3, goat bones occur within the upper $50 \mathrm{~cm}$ of most excavated trenches. The only exceptions are trenches $3 \mathrm{D}$ and $3 \mathrm{G}$, where two fragments each were recovered from $60-70 \mathrm{~cm}$. These might indicate disturbance or simply a greater depth in these squares to the upper, later horizons. On Sabtang Island, goats are present throughout the Pamayan sequence, but they are absent from the upper cultural layer in the Savidug Dune Site. If bones from Savidug Ijang site are really those of goat, as reported by Dizon (1998), then they were perhaps present there in the $12^{\text {th }}$ century AD. Taking all the current evidence into consideration, it would appear that goats were introduced to the Batanes prior to seventeenth century European contact, and must have thus been acquired from a source other than European vessels.

It is difficult to ascertain the source of the Batanes goats, but it is significant that their introduction occurred in rough correlation with the appearance of Chinese porcelain. In the Philippines, patterns of long-distance exchange, which first emerged during the later centuries $\mathrm{BC}$ and early centuries AD, began to intensify towards the mid-late first millennium AD (Bacus 2004). This timeline appears to fit with the introduction of the goat to the Batanes Islands.

Zooarchaeological records of goat are scarce throughout Mainland and Island Southeast Asia. Medway (1963) reported the discovery of a fragment of goat in the upper few inches of deposit in the West Mouth of Niah Cave. These fragments remain undated, but are undoubtedly of fairly recent origin. Glover (1986: 205) reported that Capra/Ovis remains first appear in the archaeological sequence in the cave of Uai Bobo 2, East Timor, in Horizon VII (4000-3000 BC) and Horizon IX (2000-1500 BC). He also noted that goat bones were recovered in quantity only in Uai Bobo 1 Horizon V and Uai Bobo 2 Horizon X, dated to about AD 200-600 and 500-1 $\mathrm{BC}$ respectively. We regard all these dates as probably too early for the introduction of the goat to the region, especially considering that caprines only appear in the zooarchaeological record of China at 2000 BC, and then only in small numbers (Jing and Flad 2002).

An explanation for these seemingly early records of goat in Timor might be explained by the common contemporary use of caves as goat herding pens (Sue O'Connor pers. comm.). This practice is possibly of some antiquity and could have caused considerable disturbance and reworking of goat bones into old deposits. A study of the animal remains from the indigenous fortified settlements of Vasino and Macapainara has demonstrated that goats were present there during the early to middle 15 th century $\mathrm{AD}$, and probably prior to this date (Amano and Piper 2011; Piper and Amano 2011).

Bird bones are relatively rare in the zooarchaeological assemblages, but a single fragment of bird right tibiotarsus shaft with marked similarities in both size and morphology to the chicken was recorded in Savidug Dune Site layer 4. This corresponds with a date close to 500 BC. It is possible that chickens were introduced fairly early in the prehistory of the Batanes Islands. They were certainly present when Dampier visited in 1687, albeit in rather small numbers. He wrote

Here are plenty of goats and abundance of hogs; but few fowls, either wild or tame. For this I have always observed in my travels, both in the East and West Indies, that in those places where there is plenty of grain, that is, of rice in one and maize in the other, there are also found great abundance of fowls; but on the contrary few fowls in those countries where the inhabitants feed on fruits and roots only. The few wild fowls that are here are parakeets and some other small birds. Their tame fowl are only a few cocks and hens. (Blair and Robertson 1903-9, Vol. 39, pp. 99). 
This scarcity of chickens on the islands and the propensity of fragile bird bones to break up easily might explain their rarity in the archaeological record. Bird bones also present particular identification challenges, and this tentative identification of chicken rests on a single tibiotarsus shaft. Confirmation of the presence of chickens in Batanes in prehistory awaits further identifications of well-stratified, species-diagnostic specimens.

Three fragments of $\operatorname{dog}$ (Canis lupus familiaris) from Savidug Dune Site layer 4 also indicate that this domestic animal was already present in Batanes by 2500 years ago. The recent evidence for dogs at Nagsabaran in northern Luzon dates to a similar age, and demonstrates that the domestic dog was widespread in the northern Philippines by the middle of the first millennium BC (Piper et al. 2009; Amano et al. in press). The proximal end of a dog $3^{\text {rd }}$ left metatarsal and the distal end of the same or different metapodial were recovered from Square 3, layer 4, during the 2004 Callao Cave excavation in the Peñablanca region of northern Luzon (Fig. 10.14). This layer is dated by an AMS C14 sample of charcoal to 1650-1470 cal. BC (Mijares 2006: 37). There is no evidence of wild canids ever inhabiting Luzon, and it is likely that this specimen is from a domestic dog. However, the association between the date and the bone fragments is tentative. It is not definitive evidence for a $2^{\text {nd }}$ millennium $B C$ presence of dog in the Philippines, but it suggests that earlier dog remains might yet be found in the archipelago.

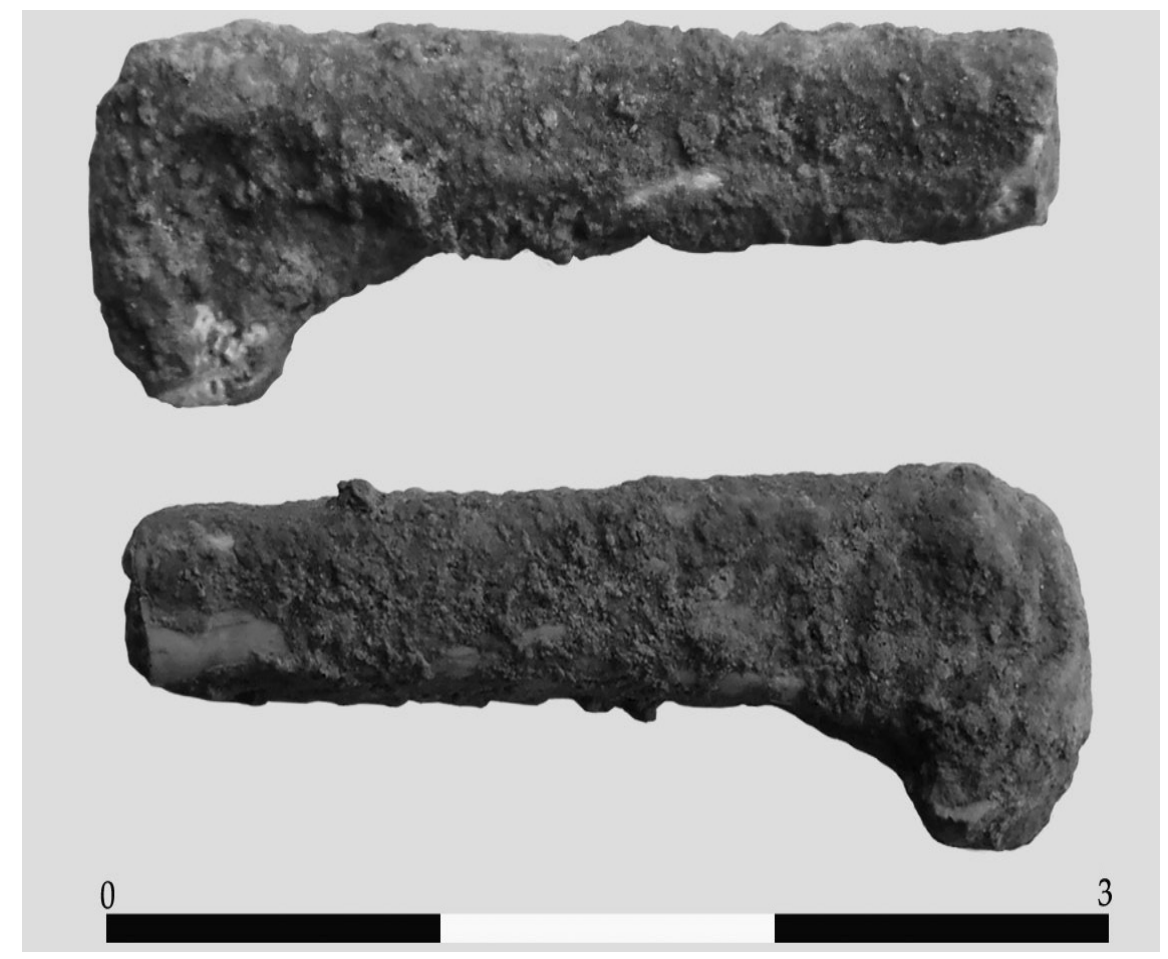

Figure 10.14. Though coated in concretion, this specimen is still identifiable as the proximal end of a dog 3rd left metatarsal, recovered from Square 3, layer 4, during the 2004 excavations at Callao Cave, northern Luzon.

Source: Philip Piper.

Cut marks on a dog right mandibular condyle from Savidug QR7-9 $(110-120 \mathrm{~cm})$ would seem to indicate that dogs were eaten, at least occasionally. This interpretation is corroborated by the journal of Jirobei (in Yamada 2007: 325), who states that men ate dog meat during his three-year stay on Batan between 1668 and 1670. This would appear to have been a dietary habit that dated back at least 2500 years. 
A fragment of deer antler tine in the Savidug Dune Site and a heavily worn deer mandibular second molar were also recovered from layer 2 suggesting the possibility that a deer population once existed on Sabtang. But this will require further verification through the recovery of more zooarchaeological remains.

Turtle remains are common in Savidug Dune Site layers 4 and 5, but are extremely scarce in layer 2. The diminishing numbers of marine turtle remains possibly reflects prehistoric over-hunting.

Jinsuke Uji (in Yamada 2007: 333) wrote of his late $17^{\text {th }}$ century Batan observation that "there are many water buffaloes which look like large cows." This suggests that the water buffalo (Bubalus bubalis) was introduced before the mid-1 $7^{\text {th }}$ century. Jinsuke Uji also visited Sabtang and noted numerous water buffalo there too. The only fragment of bovine recorded in this project was a small fragment of the proximal end of a bovine metacarpal from the subsurface of Torongan Cave, and this piece looks relatively modern. There is also a small fragment of molar column from Savidug Dune Site, at 50-60 cm (cultural layer 2), that could potentially be from a bovine. This provides very tentative evidence that bovines might have been present on Sabtang about a thousand years ago. Dampier made no reference to the presence of buffalo per se, but did indicate that 'armour' was made of buffalo hide. It is possible that bovines were introduced and later extirpated to be re-introduced again in the $18^{\text {th }}$ century. Recent analysis of a bone assemblage from the site of Nagsabaran in northern Luzon has produced evidence for a buffalo presence there as early as $500 \mathrm{BC}$ (Amano et al. in press) indicating source populations of bovines were present in the Philippines. Further archaeological research and zooarchaeological analyses are necessary to resolve the outstanding issue of the prehistoric presence of bovines in the Batanes Islands.

An interesting feature of the Itbayat assemblage is the presence of a civet cat throughout the archaeological sequence, from at least $1000 \mathrm{BC}$ to the fairly recent. There are no specimens that identify the archaeological remains with any certainty to species, but based on size and morphology it was most likely to be either the widely distributed common palm civet (Paradoxurus hermaphroditus) or the Taiwanese subspecies of masked palm civet (Paguma larvata taivana). The remoteness of the islands would suggest that the civet cat was deliberately introduced. However, independent colonization of Itbayat by civet cats without human intervention is not impossible. Esseltyn and Oliveros (2010) argue that the shrew Crocidura tanake invaded the islands of Batan and Sabtang from Taiwan in this way, and subsequently diversified.

The same civet cat is not yet recorded on Sabtang, suggesting a limited distribution across the archipelago. More definite resolution and species identification would thus have important implications for understanding prehistoric contact between the Batanes and surrounding islands. The common palm civet is absent from Taiwan and would most likely have been introduced from the Philippines, whereas there are no records of the masked palm civet in the Philippines.

The common palm civet is also known to have been translocated from the Sunda biogeographic region to certain Wallacean islands, including Sulawesi, Nusa Tenggara and the Aru Islands (Heinsohn 2003; van den Bergh et al. 2009). However, no geometric morphometric or genetic analyses have been attempted to try and find the sources of these ethnophoretic populations. The masked palm civet and common palm civet could have provided additional sources of protein and fur on islands with impoverished faunas, and both are considered excellent predators of commensal rodents (Heinsohn 2003).

The presence of rat-sized cranial and post-cranial elements indicates that rodents were active on the island from the earliest periods of human activity. A single Rattus sp. mandible from Savidug Dune Site indicates that an introduced commensal species inhabited the islands during prehistory. In addition, the zooarchaeological study has produced records of unidentified native birds, from passerine to chicken-sized, on Itbayat and Sabtang that are likely to have been part of 
the native avifauna. There was also a small snake on the former island. However, there is currently no evidence in the archaeological record for a large (4.5-4.8 m long) snake, of a size that Jinsuke Uji (in Yamada 2007: 333) claimed to be caught and eaten on Batan during the $17^{\text {th }}$ century.

\section{Acknowledgements}

The preliminary research for chapter 10 was undertaken by Shawna Hsiu-Ying Yang under the supervision of Terry O'Connor, as part of a visiting fellowship to the Department of Archaeology, University of York, UK, funded by a European Community Marie Curie MEST-CT-2005-020601 PALAEO grant. Philip Piper and Noel Amano undertook a further detailed analysis of the remains within the zooarchaeology laboratory of the Archaeological Studies Program, University of the Philippines, funded by a special grant from the Chancellor's Office to Drs Piper and Mijares as part of the Bioarchaeology Initiative. The authors of chapter 10 would like to thank the National Museum of the Philippines for permitting the zooarchaeological assemblages from the Philippines to be sent to the Department of Archaeology, University of the Philippines, for initial study. 